\title{
CETAMINA, XILAZINA E ATROPINA, EM DOSES CALCULADAS POR EXTRAPOLAÇÃO ALOMÉTRICA INTERESPECÍFICA, PARA CONTENÇÃO FARMACOLÓGICA DA CUTIA (Dasyprocta azarae)
}

\author{
José Ricardo Pachaly ${ }^{1}$ \\ Emygdio Leite de Araújo Monteiro Filho ${ }^{2}$ \\ Pedro Ribas Werner ${ }^{3}$ \\ Diogo Fernandes Giovanellli ${ }^{4}$ \\ Juliano Bortolo de Conti ${ }^{5}$ \\ Sheila Rezler Wosiacki ${ }^{6}$ \\ Salviano Tramontin Belettini ${ }^{7}$ \\ Evandra Maria Voltarelli-Pachaly ${ }^{8}$
}

PACHALY, J. R.; MONTEIRO FILHO, E. L. de A.; WERNER, P. R.; GIOVANELLI, D. F.; CONTI, J. B. de; WOSIACKI, S. R.; BELETTINI, S. T.; VOLTARELLI-PACHALY, E. M. Cetamina, xilazina e atropina, em doses calculadas por extrapolação alométrica interespecífica para contenção farmacológica da cutia (Dasyprocta azarae). Arq. Ciênc. Vet. Zool. UNIPAR, Umuarama, v. 17, n. 1, p. 11-26, jan./mar. 2014.

\begin{abstract}
RESUMO: A cutia (Dasyprocta azarae) é um roedor neotropical que necessita ser contido por meios farmacológicos para a realização de certos procedimentos médicos e de manejo, em função de características comportamentais de defesa e grande susceptibilidade ao estresse. A combinação de cloridrato de cetamina, cloridrato de xilazina e sulfato de atropina foi administrada, por via intramuscular, a 53 cutias (33 machos e 20 fêmeas) com pesos entre 0,74 e 3,58 $\mathrm{kg}(2,071 \pm 0,678 \mathrm{~kg})$, para possibilitar a realização de procedimentos de campo que incluíam determinação de sexo, biometria, marcação, exame físico e colheita de sangue e urina. Após a pesagem de cada cutia, a dose individual de cada um dos fármacos foi calculada por meio de extrapolação alométrica interespecífica, usando-se como modelo as doses usualmente recomendadas para um cão doméstico de $10 \mathrm{~kg}$ (cetamina $-20,00 \mathrm{mg} / \mathrm{kg}$, xilazina $-2,00 \mathrm{mg} / \mathrm{kg}$ e atropina - 0,05mg/kg). Em todos os animais a indução do estado de contenção foi rápida, sendo a reação postural de endireitamento abolida entre 0,5 e 5,0 minutos $(2,02 \pm 1,21$ minutos $)$ após a injeção. A temperatura retal variou de 28,9 a $40,9^{\circ} \mathrm{C}\left(36,38 \pm 2,04^{\circ} \mathrm{C}\right)$, a frequência cardíaca variou de 72 a 240 b.p.m. $(150,93 \pm 31,48$ b.p.m.) e a frequência respiratória variou de 20 a 192 m.p.m. (80,63 29,09 m.p.m.). Avaliou-se a qualidade da contenção farmacológica com base no miorrelaxamento observado aos dez, 15, 25 e 35 minutos após a injeção. A contenção farmacológica foi excelente em cerca de $90,00 \%$ dos casos, e boa em outros 5,00\%. A qualidade da analgesia foi avaliada, principalmente, por meio das reações de nocicepção ao pinçamento de um dígito do membro torácico esquerdo aos dez, 15, 25 e 35 minutos após a injeção, e foi ruim em mais de 50,00\% dos casos. Os animais se recuperaram sem apresentar distúrbios psicomotores, permanecendo calmos até recobrarem a capacidade de ambulação normal, entre 105 e $277(164,94 \pm 37,14)$ minutos após a injeção. O método proposto mostrou-se plenamente adequado à contenção farmacológica de exemplares de Dasyprocta azarae que necessitem ser submetidos a procedimentos medianamente dolorosos ou incômodos, como biometria, determinação de sexo, exame físico e colheita de sangue e urina. Não é indicado, porém, para procedimentos cirúrgicos. Este artigo resgata resultados inéditos obtidos em uma pesquisa finalizada em 1998.
\end{abstract}

PALAVRAS-CHAVE: Alometria. Anestesia. Animais selvagens. Roedores.

\section{ALLOMETRICALLY SCALED DOSAGES OF KETAMINE, XYLAZINE AND ATROPINE FOR CHEMICAL RESTRAINT OF AGOUTI (Dasyprocta azarae)}

\footnotetext{
ABSTRACT: The agouti (Dasyprocta azarae) is a neotropical rodent that requires chemical restraint for handling due to its susceptibility to stress and defensive behavior characteristics. Fifty-three agoutis (33 males and 20 females) weighing 0.74 to $3.58 \mathrm{~kg}(2.071 \pm 0.678 \mathrm{~kg})$ were given ketamine hydrochloride, xylazine hydrochloride and atropine sulfate combined by i.m. injection during field procedures that included sexing, measuring, marking, physical examinations and collecting blood and urine. All drug doses were calculated using the respective doses of a 10-kg dog as model. These doses are $20.00 \mathrm{mg} /$ $\mathrm{kg}$ for ketamine, $2.00 \mathrm{mg} / \mathrm{kg}$ for xylazine and $0.05 \mathrm{mg} / \mathrm{kg}$ for atropine. In all individuals, immobilization was rapid and uneventful. Righting reflexes were abolished after 0.50 to $5.00 \mathrm{~min}(2.02 \pm 1.21 \mathrm{~min})$. Body temperature fluctuated between 28.9 and $40.9^{\circ} \mathrm{C}\left(36.38 \pm 2.04^{\circ} \mathrm{C}\right)$, heart rates remained between 72 and 240 beats/min $(150.93 \pm 31.48)$; and respiratory rates ranged

DOI: https://doi.org/10.25110/arqvet.v17i1.2014.4912

${ }^{1}$ Médico Veterinário, Mestre, Doutor, Pós-Doutor. Programa de Mestrado em Ciência Animal da UNIPAR. Praça Mascarenhas de Moraes, s/n, Centro, Umuarama, Paraná, CEP 87502-10, Brasil. E-mail: pachaly@uol.com.br

${ }^{2}$ Biólogo, Mestre, Doutor, Pós-Doutor. Universidade Federal do Paraná. Curitiba, Paraná, Brasil. E-Mail: kmonteiro@uol.com.br

${ }^{3}$ Médico Veterinário, Mestre, Doutor, Pós-Doutor. Laboratório Werner \& Werner. Curitiba, Paraná, Brasil. E-mail: pedro.werner@gmail.com

${ }^{4}$ Médico Veterinário, Mestre. Clínica Veterinária Mourãoense. Paraná, Brazil. E-Mail: dfgiovanelli@yahoo.com.br

${ }^{5}$ Médico Veterinário, Mestre, Doutor. Universidade Estadual de Maringá - UEM. Umuarama, Paraná, Brasil. E-Mail: julianodeconti@yahoo.com.br

${ }^{6}$ Médica Veterinária, Mestre, Doutora. Universidade Estadual de Maringá - UEM. Umuarama, Paraná, Brasil. E-Mail: wosiacki@yahoo.com.br

${ }^{7}$ Médico Veterinário, Mestre. UNIPAR. E-mail: salviano@unipar.br

${ }^{8}$ Médica Veterinária, Mestre. ESPECIALVET. E-mail: emvoltarelli@hotmail.com
} 
between 20 and 192 breaths/min (80.63 \pm 29.09$)$. Restraint quality was evaluated by measuring muscle relaxation at $10,15,25$ and $35 \mathrm{~min}$ after injection. Chemical restraint was excellent in about $90.00 \%$ and good in about $5.00 \%$ of the cases. Analgesia quality was evaluated mainly by measuring the reactions to painful stimuli such as pinching of a digit in the left thoracic limb at $10,15,25$ e 35 min after injection, and was poor in more than $50.00 \%$ of the cases. Recovery occurred without psychomotor disturbances, and every animal remained calm until normal ambulation resumed between 105 and 277 min (164.94 \pm 37.14 min). The proposed method was safe for both animals and the human personnel. It is recommended for routine management and stressful but not painful medical procedures like physical examination, measuring, sexing, and urine and blood collection in D. azarae. This article rescues data obtained in an investigation performed back in 1998.

KEYWORDS: Allometrics. Anesthesia. Rodents. Wild animals.

\section{KETAMINA, XILACINA Y ATROPINA, EN DOSIS CALCULADAS POR EXTRAPOLACIÓN ALOMÉTRICA INTERESPECÍFICA, PARA SUJECIÓN FARMACOLÓGICA DEL AGUTÍ (Dasyprocta azarae)}

RESUMEN: El agutí (Dasyprocta azarae) es un roedor neo tropical que necesita ser sujetado por medios farmacológicos para ciertos procedimientos médicos y de manejo, debido a características comportamentales de defensa y gran susceptibilidad a el estrés. La combinación de clorhidrato de ketamina, clorhidrato de xilacina y sulfato de atropina fue administrada por vía intramuscular a 53 agutíes (33 machos e 20 hembras) con pesos entre 0,74 e 3,58 $\mathrm{kg}(2,071 \pm 0,678 \mathrm{~kg})$, para posibilitar la realización de procedimientos de campo que incluyan determinación de sexo, biometría, marcación, examen físico y colecta de sangre y orina. Cada animal fue pesado y la dosis individual de cada uno de los fármacos fue calculada por extrapolación alométrica interespecífica, usándose como modelo las dosis usualmente recomendadas para un perro doméstico de $10 \mathrm{~kg}$ ( $\mathrm{ketamina}-20,00 \mathrm{mg} / \mathrm{kg}$, xilacina $-2,00 \mathrm{mg} / \mathrm{kg}$ y atropina $-0,05 \mathrm{mg} / \mathrm{kg}$ ). En todos los animales la inducción del estado de sujeción fue rápida, y la reacción postural de enderechamiento fue abolida entre 0,5 e 5,0 minutos $(2,02 \pm 1,21$ minutos $)$ después de la inyección. La temperatura rectal varió de 28,9 a $40,9^{\circ} \mathrm{C}\left(36,38 \pm 2,04^{\circ} \mathrm{C}\right)$, la frecuencia cardíaca varió de 72 a 240 b.p.m. (150,93 $\pm 31,48$ b.p.m.) y la frecuencia respiratoria varió de 20 a 192 m.p.m. (80,63 29,09 m.p.m.). Se evaluó la calidad de la sujeción farmacológica, basado en el relajamiento muscular observado a los 10, 15, 25 y 35 minutos después de la inyección. La sujeción farmacológica fue excelente en casi $90,00 \%$ de los casos, y buena en otros 5,00\%. La calidad de la analgesia fue evaluada principalmente por las reacciones de sensibilidad dolorosa al pinzamiento de un dígito del miembro torácico izquierdo a los 10, 15, 25 e 35 minutos después de la inyección, y fue ruin en más de 50,00\% de los casos. Los animales se recuperaron sin presentar disturbios psicomotores, permaneciendo calmos hasta recobrar la capacidad de ambulación normal, entre 105 e $277(164,94 \pm 37,14)$ minutos después de la inyección. El método propuesto se mostró plenamente adecuado a la sujeción farmacológica de ejemplares de Dasyprocta azarae que necesiten ser sometidos a procedimientos medianamente dolorosos o incómodos, como biometría, determinación de sexo, examen físico e colecta de sangre y orina. No es indicado, entretanto, para procedimientos quirúrgicos. Este artículo rescata resultados inéditos obtenidos en una investigación finalizada en 1998.

PALABRAS CLAVE: Alometría. Anestesia. Animales salvajes. Roedores.

\section{Introdução}

Na contenção de animais selvagens, o método empregado deve oferecer plena segurança para o animal e para a equipe envolvida e, ao mesmo tempo, permitir a realização adequada de procedimentos médicos ou de manejo. Na contenção farmacológica busca-se, fundamentalmente, um estado de imobilidade e analgesia que possibilite a realização daqueles procedimentos. Contudo, profissionais que trabalham com animais selvagens defrontam com uma gama variadíssima de formas, tamanhos e taxas de metabolismo basal que lhes obriga extrapolar doses de fármacos de um animal para outro (KIRKWOOD 1983, SEDGWICK; POKRAS 1988, PACHALY, 2006). Entretanto, existe um enorme potencial de cálculo errôneo das doses dos fármacos empregados, resultando em subdosagens ou dosagens excessivas e consequentes ineficiência ou toxicidade (SEDGWICK; POKRAS 1988). Aliás, grande parte dos óbitos que ocorrem em função de procedimentos de contenção em animais selvagens deve-se a falhas nos cálculos das doses de anestésicos e sedativos.

Este artigo discute a contenção farmacológica de roedores selvagens e apresenta os resultados de um projeto de pesquisa referente ao emprego de uma associação de fármacos, em doses calculadas por meio de extrapolação alométrica interespecífica, para contenção da cutia (Dasyprocta azarae).

\section{Revisão de Literatura}

Determinados roedores, muitos deles listados como espécies ameaçadas de extinção, apresentam porte e valor que justificam cuidados especiais, e um desses roedores é a cutia (Dasyprocta azarae), espécie de ocorrência natural no sul do Brasil e muito frequente em parques zoológicos e criadouros. A manipulação desses animais é bastante difícil e, mesmo quando habituados aos tratadores e condições de cativeiro, as cutias são muito susceptíveis ao estresse, reagindo energicamente e com riscos de se ferir (LANGE; JABLONSKI 1981). Fez-se necessário, portanto, desenvolver um método de trabalho e um protocolo posológico adequado e seguro para contenção farmacológica de Dasyprocta azarae.

Neste artigo, relatam-se os resultados do emprego de uma associação de três fármacos: um anestésico dissociativo, o cloridrato de cetamina, um sedativo com propriedades analgésicas e miorrelaxantes e agonista de receptores adrenérgicos $\alpha_{2}$, o cloridrato de xilazina, e um agente anticolinérgico, o sulfato de atropina, em doses calculadas por meio de extrapolação alométrica interespecífica.

\section{Dasyprocta azarae}

As diversas espécies de cutia pertencem ao gênero Dasyprocta, que ocorre nas Américas Central e do Sul (EM- 
MONS, 1990, HONACKI et al., 1992). No Brasil, a localidade típica de Dasyprocta azarae é o Estado de São Paulo (WOODS, 1992), mas é encontrada em Minas Gerais, Mato Grosso do Sul, Paraná, Santa Catarina e Rio Grande do Sul. Ocorre também no Paraguai, nordeste da Argentina e leste da Bolívia (LANGE; JABLONSKI, 1981; WOODS, 1992). Trata-se de um animal terrícola e de atividade diurna, vivendo em florestas ou capoeiras, e alimenta-se de frutos, sementes e vegetais suculentos (SILVA, 1984).

\section{Contenção farmacológica}

Em anestesiologia, o sulfato de atropina é empregado para reduzir secreções do trato respiratório e das glândulas salivares, e para inibir os efeitos da estimulação vagal sobre os sistemas respiratório e cardiovascular (SOMA, 1971; SOMA; PENNEY, 1975). Age bloqueando o estímulo vagal induzido por respostas reflexas à tração de vísceras, à estimulação laríngea direta e o induzido por diversos agentes anestésicos e pré-anestésicos (SOMA; PENNEY, 1975; HOLZ et al., 1994). Tem também uma ação broncodilatadora, relaxando a musculatura lisa bronquial e traqueal, mas não produz alterações importantes na pressão sanguínea (SOMA; PENNEY, 1975). Diminui o peristaltismo, reduz a atividade secretora do trato digestivo (MASSONE, 1988) e, em muitas espécies animais, produz midríase (SOMA; PENNEY, 1975).

O cloridrato de xilazina é classificado como um sedativo analgésico com propriedades miorrelaxantes. Seus efeitos são aditivos, quando em combinação com outros fármacos depressores e analgésicos usados para produzir contenção farmacológica ou anestesia geral (TRANQUILI; THURMON, 1984; MASSONE, 1988; PLUMB, 1991; MUIR; HUBBEL, 1995). Em animais selvagens, o cloridrato de xilazina é bastante utilizado, tanto como agente isolado para sedação e imobilização quanto, mais comumente, para moderar os efeitos do cloridrato de cetamina.

O cloridrato de cetamina induz um estado anestésico denominado "anestesia dissociativa" (DOMINO et al., $1965)$ por interrupção do fluxo de informação das porções inconscientes para as porções conscientes do encéfalo, ao invés de deprimir de modo generalizado todos os centros encefálicos (WRIGHT, 1982). Ao contrário do que ocorre com analgésicos narcóticos, na analgesia obtida com o cloridrato de cetamina não se observam hipnose e depressão generalizada do sistema nervoso central, havendo preservação dos reflexos protetores (SOMA, 1971). O cloridrato de cetamina induz a ocorrência de catalepsia, estado caracterizado por graus variáveis de hipertonia, rigidez em extensão de membros e opistótono (BECK, 1976; SAWYER et al., 1977; MEYER-JONES et al., 1983). Podem ocorrer movimentos mioclônicos e contrações musculares esporádicas, não relacionados com estímulos dolorosos (WHITE et al., 1982; MEYER-JONES et al., 1983), os quais podem ser minimizados com a utilização de fármacos como os agonistas de receptores adrenérgicos $\alpha_{2}$ como o cloridrato de xilazina (SEDGWICK, 1979; SEDGWICK, 1980; WRIGHT, 1982; FOWLER, 1986; PLUMB, 1991; PACHALY, 1994; MUIR; HUBBEL, 1995). Observa-se nistagmo lento e dilatação pupilar, com reflexos fotomotores e corneanos preservados (SOMA, 1975; MEYER-JONES et al., 1983). Em diversas espécies ocorre salivação abundante, que pode ser controlada com a utilização do sulfato de atropina (STUNKARD; MILLER, 1974; BECK, 1976; WRIGHT, 1982; FOWLER, 1986; WHITE; FIELD, 1987; PACHALY, 1992; HOLZ et al., 1994). O cloridrato de cetamina aumenta a frequência cardíaca e o rendimento cardíaco, bem como provoca vasoconstrição periférica e elevação da pressão arterial. Esses efeitos podem ser considerados benéficos, uma vez que um risco primário de outros agentes anestésicos é justamente a depressão global dos sistemas autonômico e cardiovascular (WRIGHT, 1982; MASSONE, 1988). Os reflexos laríngeo e faríngeo são mantidos durante a anestesia pelo cloridrato de cetamina, tanto em gatos (SOMA, 1971) quanto nas outras espécies domésticas (WRIGHT, 1982).

A utilização do cloridrato de cetamina como agente anestésico único na maioria das espécies domésticas e selvagens não é recomendável em função de seus diversos efeitos colaterais. A fim de potencializar os efeitos vantajosos do cloridrato de cetamina e minimizar os efeitos indesejáveis, recomenda-se a associação com outros fármacos (SOMA; PENNEY 1975; SAWYER et al., 1977; SEDGWICK, 1979; STOSKOPF, 1979; SEDGWICK, 1980; WRIGHT, 1982; MEYER-JONES et al. 1983; WALLACH; BOEVER 1983; CLARK; OLFERT 1986; FOWLER, 1986; WHITE; FIELD 1987; SEDGWICK, 1988; MANDSAGER; RAFFE 1989; PLUMB, 1991; HARTSFIELD, 1992; MUIR; HUBBEL, 1995). Uma das maneiras de reduzir os efeitos indesejáveis da utilização isolada do cloridrato de cetamina é sua associação a agonistas de receptores adrenérgicos $\alpha_{2}$ (NAVARRO; FRIEDMAN, 1975, BACHER et al., 1976; CULLEN; JONES, 1977; KAPLAN, 1979; SEDGWICK, 1979; SEDGWICK, 1980; WRIGHT, 1992; MEYER-JONES et al., 1983; WALLACH; BOEVER, 1983; FIALHO, 1985; FOWLER, 1986; LÉONARD, 1986; ALLERT; ADAMS, 1987; THURMON; BENSON, 1987; WHITE; FIELD, 1987; WIXSON et al., 1987; MASSONE, 1988; MANDSAGER; RAFFE, 1989; SCHUCHMAN, 1989; BELANT, 1991; PLUMB, 1991; HASKINS, 1992; KLIDE, 1992; TRANQUILI; BENSON, 1983; JALANKA, 1993; ARNEMO et al., 1994; BÓ et al., 1994; FERRERAS et al., 1994; GARNER; ADDISON, 1994; HOLZ et al., 1994; PACHALY, 1994; ARNEMO; SOLI, 1995; BAILEY et al., 1995; BELTRÁN; TEWES, 1995; MATTHEWS et al., 1995; MUIR; HUBBEL, 1995; BELANT, 1996; HEARD et al., 1996; NICHOLLS et al., 1996; OSOFSKY et al., 1996) e ao sulfato de atropina (STUNKARD; MILLER, 1974; BECK, 1976; WRIGHT, 1982; FOWLER, 1986; WHITE; FIELD, 1987; PLUMB, 1991; HOLZ et al., 1994; MUIR; HUBBEL, 1995). O cloridrato de xilazina, por sua vez, como outros agonistas de receptores adrenérgicos $\alpha_{2}$ induz hipotensão e bradicardia, que podem ser controladas de maneira eficiente, mediante o emprego concomitante do sulfato de atropina (PLUMB, 1991; HOLZ et al. 1994).

A literatura mostra extrema variabilidade no que diz respeito à posologia do cloridrato de cetamina em uso isolado ou em combinação com outros fármacos para animais selvagens. Segundo Fowler (1986), a dose para imobilização de espécies selvagens varia de 2,0 a $50,0 \mathrm{mg} / \mathrm{kg}$. Quanto ao seu emprego em roedores selvagens as citações são ainda mais escassas, especialmente no que concerne às espécies neotropicais. As doses recomendadas apresentam uma varia- 
bilidade ainda maior, entre 5,0 e 120,0mg/kg (STUNKARD; MILLER, 1974; BECK, 1976; BACHER et al., 1976; STOSKOPF, 1979; SEDGWICK, 1980; GENEVOIS et al., 1984; CLARK; OLFERT, 1986; FRASE; VAN VUREN, 1989; SCHUCHMAN, 1989; PACHALY, 1992; 1994; 1996). Uma falha adicional encontrada na literatura é o fato de que vários autores propõem protocolos posológicos, porém não fazem referência aos resultados obtidos.

De maneira geral, a avaliação da contenção farmacológica é feita por meio de estimulação dolorosa, como o pinçamento da pele da região interdigital, das bordas das orelhas, da região abdominal e da cauda, para avaliar a sensibilidade superficial (SOMA, 1971; FIALHO, 1985; WHITE; FIELD, 1987) ou do dígito, incluindo a parte óssea, para avaliar a sensibilidade profunda (CHRISMAN, 1998). A profundidade anestésica é avaliada pelo relaxamento muscular e movimentação espontânea do paciente. Em se tratando de roedores selvagens, Pachaly (1998) definiu parâmetros para avaliação da contenção farmacológica pela associação cloridrato de cetamina, maleato de acetilpromazina e sulfato de atropina em Cuniculus (Agouti) paca, sob condições clínicas reais de exame físico e outros procedimentos médicos, padronizou o método e o indicou para mamíferos domésticos e selvagens. $\mathrm{O}$ autor avaliou tanto a qualidade da contenção, classificando o estado anestésico pelo grau de analgesia, grau de miorrelaxamento e a profundidade da anestesia, quanto o tempo de contenção e a qualidade da recuperação do paciente.

\section{Extrapolação alométrica interespecífica}

Praticar medicina de animais selvagens significa trabalhar com variada gama de formas, tamanhos e taxas de metabolismo basal, e consequentes respostas farmacológicas diferentes (KIRKWOOD, 1983; SEDGWICK; POKRAS, 1988). Em função dessa variabilidade, existe grande potencial de cálculo errôneo de doses dos fármacos empregados, resultando em subdosagens ou dosagens excessiva, e ineficiência ou toxicidade (SEDGWICK; POKRAS, 1988). Aliás, grande parte dos óbitos de animais; selvagens ocorridos em função de procedimentos de contenção deriva de cálculos feitos de modo empírico, adaptando-se doses conhecidas para animais domésticos sem levar em consideração as diferenças metabólicas entre as espécies envolvidas. Devido à dificuldade de condução de experimentos farmacológicos em espécies selvagens, são escassas as informações sobre doses de fármacos a serem empregadas nesses animais, sendo desejáveis métodos racionais para cálculos de doses. Uma alternativa eficiente consiste na comparação de animais de espécies diferentes com base em sua taxa metabólica basal, e a extrapolação de doses já definidas para uma delas para indivíduos da outra espécie. Esse método, denominado extrapolação alométrica interespecífica, permite o estabelecimento de protocolos terapêuticos racionais (PACHALY; BRITO, 2001; PACHALY, 2006)

Alometria é o estudo da dependência de uma variável, como a taxa metabólica ou qualquer função de um sistema orgânico qualquer em relação a uma variável independente, como a massa corpórea. A base dos cálculos alométricos é a taxa metabólica basal (TMB), que é determinada pelo produto da massa corpórea $(\mathrm{M})$ em quilogramas por uma constante de proporcionalidade $(\mathrm{K})$, taxonomicamente dependente e baseada na temperatura corporal central do animal (TMB $=$ M.K). Inicialmente, um animal de massa conhecida e para o qual existem dados confiáveis a respeito do fármaco de interesse é definido como animal modelo. A seguir calculam-se as TMB do animal modelo e do animal alvo. Multiplicando-se a dose (já conhecida) para o animal modelo pela sua TMB, obtém-se a dose por quilocaloria do fármaco de interesse. Multiplicando-se o valor da TMB do animal alvo pela dose por quilocaloria previamente obtida obtém-se a dose do fármaco de interesse para o animal alvo (PACHALY; BRITO, 2001; PACHALY, 2006). No caso de tratamentos prolongados, a frequência de administração das doses também pode ser calculada pelo mesmo método.

\section{Material e Método}

Foram utilizados 53 exemplares saudáveis de Dasyprocta azarae provenientes do Criadouro Científico do Museu de História Natural do Departamento de Zoológico da Secretaria Municipal do Meio Ambiente da Prefeitura Municipal de Curitiba; sendo 33 machos e 20 fêmeas, pesando entre $0,74 \mathrm{~kg}$ e $3,58 \mathrm{~kg}(2,071 \pm 0,678 \mathrm{~kg})$. Após captura com um puçá, os animais eram transferidos para um saco de pano, pesados e a seguir submetidos à contenção farmacológica.

Cada animal recebeu uma dose de uma associação de cloridrato de cetamina ${ }^{1}$, em solução a $10,00 \%$, cloridrato de xilazina ${ }^{2}$, em solução a $2,00 \%$, e sulfato de atropina ${ }^{3}$, em solução a $0,05 \%$. As doses a serem administradas foram calculadas por meio de extrapolação alométrica interespecíficas. Segundo Pachaly e Brito (2001) e Pachaly (2006), com base no peso individual e na constante energética referente a seu grupo taxonômico, utilizando o cão doméstico, com peso padrão de $10,0 \mathrm{~kg}$, como animal modelo. As doses empregadas para cães e utilizadas como modelo neste experimento, foram definidas a partir das indicações de Papich (1995) para o cloridrato de xilazina $(2,0 \mathrm{mg} / \mathrm{kg})$ e cloridrato de cetamina $(10,0 \mathrm{mg} / \mathrm{kg})$, e de Plumb (1991) para o sulfato de atropina $(0,05 \mathrm{mg} / \mathrm{kg})$.

Para facilitar as dosagens, foi elaborada uma ficha de campo contendo as doses previamente calculadas para cada uma dos fármacos empregados no experimento, para exemplares de Dasyprocta azarae com pesos entre $0,50 \mathrm{~kg}$ e 4,00 kg, a intervalos de 0,10 kg (Quadro 1).

\footnotetext{
${ }^{1}$ Francotar, Virbac, São Paulo.

${ }^{2}$ Rompum, Bayer, São Paulo.

${ }^{3}$ Sulfato de Atropina $0,5 \mathrm{mg}$, Geyer, Porto Alegre.
} 
Quadro 1: Doses de cetamina, xilazina e atropina, calculadas por meio de extrapolação alométrica interespecífica, a partir das doses para o cão doméstico (Canis familiaris), indicadas para administração a exemplares de cutias (Dasyprocta azarae) com pesos entre 0,50 e $4,00 \mathrm{~kg}$, a intervalos de $0,05 \mathrm{~kg}$

\begin{tabular}{|c|c|c|c|c|c|c|}
\hline Peso (kg) & $\begin{array}{l}\text { Dose de clori- } \\
\text { drato de cetami- } \\
\text { na, em mg/kg }\end{array}$ & $\begin{array}{c}\text { Dose total de } \\
\text { cloridrato de } \\
\text { cetamina a } 10 \% \text {, } \\
\text { em mL }\end{array}$ & $\begin{array}{l}\text { Dose de clori- } \\
\text { drato de xilazi- } \\
\text { na, em } \mathrm{mg} / \mathrm{kg}\end{array}$ & $\begin{array}{l}\text { Dose total de } \\
\text { cloridrato de } \\
\text { xilazina a } 2 \% \text {, } \\
\text { em mL }\end{array}$ & $\begin{array}{c}\text { Dose de sulfato } \\
\text { de atropina, em } \\
\mathrm{mg} / \mathrm{kg}\end{array}$ & $\begin{array}{l}\text { Dose total de } \\
\text { sulfato de atro- } \\
\text { pina a } 0,05 \% \text {, } \\
\text { em mL }\end{array}$ \\
\hline 0,50 & 42,295 & 0,211 & 4,229 & 0,106 & 0,106 & 0,053 \\
\hline 0,60 & 40,410 & 0,242 & 4,041 & 0,121 & 0,101 & 0,061 \\
\hline 0,70 & 38,883 & 0,272 & 3,888 & 0,136 & 0,097 & 0,068 \\
\hline 0,80 & 37,606 & 0,301 & 3,761 & 0,150 & 0,094 & 0,075 \\
\hline 0,90 & 36,515 & 0,329 & 3,651 & 0,164 & 0,091 & 0,082 \\
\hline 1,00 & 35,566 & 0,356 & 3,557 & 0,178 & 0,089 & 0,089 \\
\hline 1,10 & 34,728 & 0,382 & 3,473 & 0,191 & 0,087 & 0,096 \\
\hline 1,20 & 33,981 & 0,408 & 3,398 & 0,204 & 0,085 & 0,102 \\
\hline 1,30 & 33,308 & 0,433 & 3,331 & 0,216 & 0,083 & 0,108 \\
\hline 1,40 & 32,696 & 0,458 & 3,270 & 0,229 & 0,082 & 0,114 \\
\hline 1,50 & 32,137 & 0,482 & 3,214 & 0,241 & 0,080 & 0,121 \\
\hline 1,60 & 31,623 & 0,506 & 3,162 & 0,253 & 0,079 & 0,126 \\
\hline 1,70 & 31,147 & 0,530 & 3,115 & 0,265 & 0,078 & 0,132 \\
\hline 1,80 & 30,705 & 0,553 & 3,071 & 0,276 & 0,077 & 0,138 \\
\hline 1,90 & 30,293 & 0,576 & 3,029 & 0,288 & 0,076 & 0,144 \\
\hline 2,00 & 29,907 & 0,598 & 2,991 & 0,299 & 0,075 & 0,150 \\
\hline 2,10 & 29,544 & 0,620 & 2,954 & 0,310 & 0,074 & 0,155 \\
\hline 2,20 & 29,203 & 0,642 & 2,920 & 0,321 & 0,073 & 0,161 \\
\hline 2,30 & 28,880 & 0,664 & 2,888 & 0,332 & 0,072 & 0,166 \\
\hline 2,40 & 28,574 & 0,686 & 2,857 & 0,343 & 0,071 & 0,171 \\
\hline 2,50 & 28,284 & 0,707 & 2,828 & 0,354 & 0,071 & 0,177 \\
\hline 2,60 & 28,008 & 0,728 & 2,801 & 0,364 & 0,070 & 0,182 \\
\hline 2,70 & 27,745 & 0,749 & 2,775 & 0,375 & 0,069 & 0,187 \\
\hline 2,80 & 27,494 & 0,770 & 2,749 & 0,385 & 0,069 & 0,192 \\
\hline 2,90 & 27,254 & 0,790 & 2,725 & 0,395 & 0,068 & 0,198 \\
\hline 3,00 & 27,024 & 0,811 & 2,702 & 0,405 & 0,068 & 0,203 \\
\hline 3,10 & 26,803 & 0,831 & 2,680 & 0,415 & 0,067 & 0,208 \\
\hline 3,20 & 26,591 & 0,851 & 2,659 & 0,425 & 0,066 & 0,213 \\
\hline 3,30 & 26,388 & 0,871 & 2,639 & 0,435 & 0,066 & 0,218 \\
\hline 3,40 & 26,191 & 0,891 & 2,619 & 0,445 & 0,065 & 0,223 \\
\hline 3,50 & 26,002 & 0,910 & 2,600 & 0,455 & 0,065 & 0,228 \\
\hline 3,60 & 25,820 & 0,930 & 2,582 & 0,465 & 0,065 & 0,232 \\
\hline 3,70 & 25,644 & 0,949 & 2,564 & 0,474 & 0,064 & 0,237 \\
\hline 3,80 & 25,473 & 0,968 & 2,547 & 0,484 & 0,064 & 0,242 \\
\hline 3,90 & 25,308 & 0,987 & 2,531 & 0,494 & 0,063 & 0,247 \\
\hline 4,00 & 25,149 & 1,006 & 2,515 & 0,503 & 0,063 & 0,251 \\
\hline
\end{tabular}

Os fármacos eram acondicionados em uma mesma seringa e injetadas por via intramuscular profunda na musculatura da coxa dos animais, por meio do saco de contenção, após embebição do pano do saco e da pele e pêlos subjacentes com álcool iodado.

O momento da injeção foi considerado o "tempo zero" e todos os procedimentos e observações subsequentes foram registrados em "minutos pós-injeção". Após a indução da contenção farmacológica as cutias eram retiradas do saco de captura, colocadas sobre uma mesa em decúbito lateral direito e submetidas à exame físico que consistiu de inspeção visual do tegumento e da cavidade oral, palpação abdominal, ausculta cardíaca e pulmonar e termometria retal, e exame anestesiológico. 
O exame anestesiológico foi idealizado especificamente para este estudo, a partir das indicações de Pachaly (1998), e realizado aos cinco, dez, 25, 35, 45, 55, 65, 75, 85, 95,105 e 115 minutos. Nestes tempos, também foram registrados os dados referentes temperatura retal e às frequências cardíaca e respiratória, o fluxo salivar e o diâmetro pupilar, bem como realizada a irrigação oftálmica com solução fisiológica de cloreto de sódio para evitar dessecação das córneas. No $20^{\circ}$ minuto colheu-se uma amostra de sangue de todos os animais por meio de punção da veia safena lateral, como indicado por Pachaly et al. (2001) e no trigésimo minuto todos os animais foram marcados para identificação por picotes ou perfurações nas orelhas utilizando-se uma tesoura cirúrgica, conforme preconizado por Lange (1998).

A nocicepção foi avaliada pela resposta à compressão da pele da orelha, da região abdominal, de uma membrana interdigital do membro torácico e do membro pélvico e de um dígito do membro torácico e do membro pélvico com uma pinça hemostática sem dentes. Elegeu-se a reação de nocicepção à compressão de um dígito do membro torácico esquerdo, juntamente com a reação à punção venosa para colheita de sangue e à marcação das orelhas, como padrão para avaliação da analgesia. Esses parâmetros, aliados ao grau de miorrelaxamento, foram utilizados para avaliar a qualidade da contenção farmacológica. As reações à compressão do dígito foram avaliadas aos dez, 15, 25 e 35 minutos, a reação à colheita de sangue por punção de uma veia safena lateral aos 20 minutos, a reação à marcação das orelhas, aos 30 minutos e a qualidade miorrelaxamento observado aos dez, 15, 25 e 35 minutos após a injeção da associação de fármacos.

A qualidade da analgesia foi considerada "excelente" (A) quando da ausência de reações de sensibilidade, "boa" (B) quando o animal apresentou reação dolorosa moderada, com discreta movimentação do corpo, discreto tremor muscular e discreta resistência aos testes, e "ruim" (C) quando o animal apresentou reação dolorosa intensa, caracterizada por situações de evidente desconforto, com vocalização e/ou vigorosa movimentação do corpo. A qualidade do miorrelaxamento foi considerada "excelente" (A) quando da perda total do tono muscular, com ausência de tremores e/ou rigidez, "boa" (B) quando observada moderada manutenção do tono muscular, com discreta presença de tremores e/ou rigidez, e "ruim" (C) quando o animal apresentou estado de catalepsia ou movimentação intensa. A qualidade da contenção farmacológica foi considerada "excelente" (A) quando o animal apresentou miorrelaxamento excelente e imobilidade total independentemente do nível de analgesia, evidenciando a possibilidade de realização dos procedimentos médicos e de manejo usuais na rotina de parques zoológicos e criadouros, "boa" (B) quando o animal apresentou bom miorrelaxamento e moderada reação à manipulação, com discreta movimentação voluntária, mas ainda sendo possível a realização de procedimentos médicos usuais sem o uso concomitante de meios físicos de contenção, e "ruim" (C) se o animal apresentou miorrelaxamento ruim, resistência à manipulação com movimentação voluntária e impossibilitando a realização de procedimentos médicos sem o uso concomitante de meios físicos de contenção.

Quando se tornava impossível sua manipulação sem riscos, a cutia era transferida para uma caixa de observação, feita de PVC semitransparente e provida de orifícios laterais e uma porta de grade metálica. Quando capaz de manter-se em estação e movimentar-se dentro da caixa, era devolvida a seu recinto de origem, sendo observada até que exibisse ambulação normal.

A qualidade da recuperação foi avaliada desde o momento em que cada animal foi colocado na caixa de observação até que, já no recinto, exibisse ambulação normal. Para isso, foram avaliados quatro parâmetros, pormenorizados no Quadro 2. Com base nessa avaliação, a qualidade da recuperação recebia a conceituação "excelente" (A) quando o animal se mantinha calmo e repousando tranquilamente durante todo o período de recuperação, conceito "bom" (B) quando o animal apresentava moderada excitação psicomotora, e conceito "ruim" (C) quando o animal apresentava graves "reações de despertar", com agitação, tremores, mioclonia e/ou convulsões.

Quadro 2: Parâmetros utilizados para avaliação da recuperação de 53 exemplares de Dasyprocta azarae contidos pela associação cetamina, xilazina e atropina, e suas características

\begin{tabular}{|l|l|}
\hline Parâmetro & Característica \\
\hline Início do despertar & $\begin{array}{l}\text { Início da ocorrência de reações } \\
\text { conscientes à estimulação por ma- } \\
\text { nipulação do corpo, sopros na face } \\
\text { e ruídos externos. }\end{array}$ \\
\hline $\begin{array}{l}\text { Momento da impos- } \\
\text { sibilidade de mani- } \\
\text { pulação }\end{array}$ & $\begin{array}{l}\text { Momento em que a manipulação } \\
\text { dos animais tornou-se impossivel, } \\
\text { em função da intensidade das rea- } \\
\text { ções }\end{array}$ \\
\hline Despertar & $\begin{array}{l}\text { Momento em que se observou o } \\
\text { retorno da reação postural de endi- } \\
\text { reitamento }\end{array}$ \\
\hline $\begin{array}{l}\text { Retorno à ambulação } \\
\text { normal }\end{array}$ & $\begin{array}{l}\text { Momento em que se observou o re- } \\
\text { torno da capacidade de ambulação } \\
\text { normal }\end{array}$ \\
\hline
\end{tabular}

Os dados referentes à perda da reação postural de endireitamento, frequência cardíaca, frequência respiratória, temperatura retal, início do despertar, momento da impossibilidade de manipulação, momento do despertar e retorno à ambulação normal foram expressos por médias e desvios-padrão das estimativas $( \pm \mathrm{s})$.

Para avaliação da influência dos fatores tempo e sexo sobre as médias dos parâmetros analisados, foram realizados testes de análise de variância (ANOVA) e de análise multivariada de variância (MANOVA). A homogeneidade das variâncias observadas foi avaliada por meio do teste de Bartlet $\left(\mathrm{X}^{2}\right)$. O miorrelaxamento e as reações de nocicepção foram analisados por meio de tabelas de frequência.

\section{Resultados}

Indução da contenção farmacológica

O tempo para perda da reação postural de endireitamento, após a qual foi possível o início da manipulação dos animais, variou de 0,5 a 5,0 minutos após a injeção da combinação de fármacos, com média de $2,02 \pm 1,21$ minutos. A análise de variância demonstrou que houve diferença significativa $(\mathrm{p}<0,05)$ entre machos e fêmeas $(\mathrm{F}=4,9541, \mathrm{GL}=52$, $\mathrm{p}=0,0304)$ e o teste de Bartlett mostrou a homogeneidade das 
variâncias $\left(\mathrm{X}^{2}=3,115499\right)$.

\section{Parâmetros vitais}

A frequência cardíaca dos animais variou de 72 a 240 bpm $(150,93 \pm 31,48)$, sendo que a média, aos cinco minutos, era de $169 \mathrm{bpm}$, decrescendo para $135 \mathrm{bpm}$ aos 105 minutos. A análise de variância mostrou que não houve diferença significativa $(p>0,05)$ entre as frequências de machos e fêmeas $(\mathrm{F}=1,20, \mathrm{GL}=52, \mathrm{p}=0,273)$ e o teste de Bartlett mostrou a homogeneidade das variâncias $\left(\mathrm{X}^{2}=29,58\right)$.

A frequência respiratória dos animais variou de 20 a 192 movimentos respiratórios por minuto $(80,63 \pm 29,09)$. A análise de variância mostrou que houve diferença significativa $(\mathrm{p}<0,05)$ entre as frequências de machos e fêmeas $(\mathrm{F}=7,34, \mathrm{GL}=52, \mathrm{p}=0,007)$ e o teste de Bartlett mostrou a homogeneidade das variâncias $\left(\mathrm{X}^{2}=61,62\right)$.

A temperatura retal dos animais variou de 28,9 a $40,9^{\circ} \mathrm{C}(36,38 \pm 2,04)$, sendo em média de aproximadamente $38,0^{\circ} \mathrm{C}$ aos cinco minutos, e decrescendo para $33,5^{\circ} \mathrm{C}$ aos 115 minutos. Para as fêmeas, ocorreram dois momentos, aos 75 e aos 115 minutos, em que houve um aumento de aproximadamente $1,2^{\circ} \mathrm{C}$ em relação aos machos. A análise de variância mostrou que houve diferença significativa $(p<0,05)$ entre as temperaturas de machos e fêmeas $(\mathrm{F}=22,59, \mathrm{GL}=52$, $\mathrm{p}=0,001)$ e o teste de Bartlett mostrou a homogeneidade das variâncias $\left(\mathrm{X}^{2}=55,31\right)$.

Todos os animais $(100,00 \%)$ mantiveram os olhos abertos no decorrer da contenção farmacológica e, quanto aos reflexos pupilares, apresentaram dilatação pupilar fixa. Com respeito à salivação, não foi observada sialorreia em nenhum dos animais $(0,00 \%)$.

\section{Nocicepção}

As reações de nocicepção à compressão da pele segundo a intensidade da reação durante a vigência da contenção farmacológica são apresentadas no Quadro 2, enquanto o Quadro 3 apresenta as reações à compressão de um dígito do membro torácico esquerdo, eleito como padrão para avaliação da analgesia obtida durante a contenção farmacológica, juntamente com a reação à punção venosa, para colheita de sangue, e à marcação da(s) orelha(s), e o Quadro 4 apresenta as reações de nocicepção de exemplares de Dasyprocta azarae contidos pela associação cetamina, xilazina e atropina, à compressão de um dígito dos membros torácico e pélvico esquerdos, e da pele da região abdominal lateral esquerda.

A análise de variância mostrou que não houve diferença significativa $(p>0,05)$ entre as reações de machos e fêmeas $(F=3,74, G L=52, p=0,06)$. Aos 55 minutos observou-se a maior frequência de animais manifestando reação do tipo "C" $(67,92 \%)$.

Quadro 3: Reações de nocicepção segundo a intensidade da reação de exemplares de Dasyprocta azarae contidos pela associação cetamina, xilazina e atropina, à compressão da orelha esquerda e de uma membrana interdigital dos membros torácico e pélvico esquerdos, conforme o tempo após a injeção $(n=53)$

\begin{tabular}{|c|c|c|c|c|c|c|c|c|c|}
\hline \multirow[t]{2}{*}{$\mathbf{T}$} & \multicolumn{3}{|c|}{$\begin{array}{c}\text { Reação à compressão da orelha } \\
\text { esquerda }\end{array}$} & \multicolumn{3}{|c|}{$\begin{array}{l}\text { Reação à compressão de uma } \\
\text { membrana interdigital do mem- } \\
\text { bro torácico esquerdo }\end{array}$} & \multicolumn{3}{|c|}{$\begin{array}{l}\text { Reação à compressão de uma } \\
\text { membrana interdigital do mem- } \\
\text { bro pélvico esquerdo }\end{array}$} \\
\hline & $\mathbf{A}$ & B & $\mathbf{C}$ & $\mathbf{A}$ & B & C & $\mathbf{A}$ & B & $\mathrm{C}$ \\
\hline 5 & $\begin{array}{c}9 \\
(16,98 \%)\end{array}$ & $\begin{array}{c}6 \\
(11,32 \%)\end{array}$ & $\begin{array}{c}38 \\
(71,70 \%)\end{array}$ & $\begin{array}{c}23 \\
(43,40 \%)\end{array}$ & $\begin{array}{c}13 \\
(24,53 \%)\end{array}$ & $\begin{array}{c}17 \\
(32,08 \%)\end{array}$ & $\begin{array}{c}17 \\
(32,08 \%)\end{array}$ & $\begin{array}{c}11 \\
(20,75 \%)\end{array}$ & $\begin{array}{c}19 \\
(35,85 \%)\end{array}$ \\
\hline 10 & $\begin{array}{c}16 \\
(30,19 \%)\end{array}$ & $\begin{array}{c}9 \\
(16,98 \%)\end{array}$ & $\begin{array}{c}27 \\
(50,94 \%)\end{array}$ & $\begin{array}{c}25 \\
(47,17 \%)\end{array}$ & $\begin{array}{c}17 \\
(32,08 \%)\end{array}$ & $\begin{array}{c}11 \\
(20,75 \%)\end{array}$ & $\begin{array}{c}32 \\
(60,38 \%)\end{array}$ & $\begin{array}{c}8 \\
(15,09 \%) \\
\end{array}$ & $\begin{array}{c}13 \\
(24,53 \%)\end{array}$ \\
\hline 15 & $\begin{array}{c}19 \\
(35,85 \%)\end{array}$ & $\begin{array}{c}14 \\
(26,42 \%)\end{array}$ & $\begin{array}{c}20 \\
(37,74 \%)\end{array}$ & $\begin{array}{c}32 \\
(60,38 \%)\end{array}$ & $\begin{array}{c}12 \\
(22,64 \%)\end{array}$ & $\begin{array}{c}9 \\
(16,98 \%)\end{array}$ & $\begin{array}{c}39 \\
(73,58 \%)\end{array}$ & $\begin{array}{c}8 \\
(15,09 \%)\end{array}$ & $\begin{array}{c}6 \\
(11,32 \%)\end{array}$ \\
\hline 25 & $\begin{array}{c}13 \\
(24,53 \%)\end{array}$ & $\begin{array}{c}15 \\
(28,30 \%)\end{array}$ & $\begin{array}{c}25 \\
(47,17 \%)\end{array}$ & $\begin{array}{c}27 \\
(50,94 \%)\end{array}$ & $\begin{array}{c}16 \\
(30,19 \%)\end{array}$ & $\begin{array}{c}10 \\
(18,87 \%)\end{array}$ & $\begin{array}{c}37 \\
(69,81 \%)\end{array}$ & $\begin{array}{c}10 \\
(18,87 \%)\end{array}$ & $\begin{array}{c}6 \\
(11,32 \%)\end{array}$ \\
\hline 35 & $\begin{array}{c}9 \\
(16,98 \%)\end{array}$ & $\begin{array}{c}17 \\
(32,08 \%)\end{array}$ & $\begin{array}{c}27 \\
(50,94 \%)\end{array}$ & $\begin{array}{c}25 \\
(47,17 \%) \\
\end{array}$ & $\begin{array}{c}14 \\
(26,42 \%)\end{array}$ & $\begin{array}{c}14 \\
(26,42 \%)\end{array}$ & $\begin{array}{c}35 \\
(66,04 \%)\end{array}$ & $\begin{array}{c}10 \\
(18,87 \%)\end{array}$ & $\begin{array}{c}8 \\
(15,09 \%)\end{array}$ \\
\hline 45 & $\begin{array}{c}11 \\
(20,75 \%)\end{array}$ & $\begin{array}{c}14 \\
(26,42 \%)\end{array}$ & $\begin{array}{c}27 \\
(50,94 \%)\end{array}$ & $\begin{array}{c}14 \\
(26,42 \%) \\
\end{array}$ & $\begin{array}{c}21 \\
(39,62 \%)\end{array}$ & $\begin{array}{c}17 \\
(32,08 \%)\end{array}$ & $\begin{array}{c}30 \\
(56,60 \%) \\
\end{array}$ & $\begin{array}{c}13 \\
(24,53 \%) \\
\end{array}$ & $\begin{array}{c}9 \\
(16,98 \%)\end{array}$ \\
\hline 55 & $\begin{array}{c}10 \\
(18,87 \%)\end{array}$ & $\begin{array}{c}14 \\
(26,42 \%)\end{array}$ & $\begin{array}{c}29 \\
(54,72 \%)\end{array}$ & $\begin{array}{c}11 \\
(20,75 \%)\end{array}$ & $\begin{array}{c}11 \\
(20,75 \%)\end{array}$ & $\begin{array}{c}28 \\
(52,83 \%)\end{array}$ & $\begin{array}{c}14 \\
(26,42 \%)\end{array}$ & $\begin{array}{c}13 \\
(24,53 \%)\end{array}$ & $\begin{array}{c}17 \\
(32,08 \%)\end{array}$ \\
\hline 65 & $5(9,43 \%)$ & $\begin{array}{c}14 \\
(26,42 \%)\end{array}$ & $\begin{array}{c}27 \\
(50,94 \%)\end{array}$ & $\begin{array}{c}6 \\
(11,32 \%)\end{array}$ & $\begin{array}{c}12 \\
(22,64 \%)\end{array}$ & $\begin{array}{c}28 \\
(52,83 \%)\end{array}$ & $\begin{array}{c}10 \\
(18,87 \%)\end{array}$ & $\begin{array}{c}12 \\
(22,64 \%)\end{array}$ & $\begin{array}{c}24 \\
(45,28 \%)\end{array}$ \\
\hline 75 & $5(9,43 \%)$ & $\begin{array}{c}13 \\
(24,53 \%) \\
\end{array}$ & $\begin{array}{c}22 \\
(41,51 \%)\end{array}$ & $3(5,66 \%)$ & $\begin{array}{c}13 \\
(24,53 \%) \\
\end{array}$ & $\begin{array}{c}22 \\
(41,51 \%)\end{array}$ & $3(5,66 \%)$ & $\begin{array}{c}13 \\
(24,53 \%) \\
\end{array}$ & $\begin{array}{c}22 \\
(41,51 \%)\end{array}$ \\
\hline 85 & $0(0,00 \%)$ & $\begin{array}{c}10 \\
(18,87 \%)\end{array}$ & $\begin{array}{c}21 \\
(39,62 \%)\end{array}$ & $3(5,66 \%)$ & $\begin{array}{c}8 \\
(15,09 \%) \\
\end{array}$ & $\begin{array}{c}20 \\
(37,74 \%)\end{array}$ & $2(3,77 \%)$ & $5(9,43 \%)$ & $\begin{array}{c}24 \\
(45,28 \%)\end{array}$ \\
\hline 95 & $1(1,89 \%)$ & $\begin{array}{c}6 \\
(11,32 \%)\end{array}$ & $\begin{array}{c}17 \\
(32,08 \%)\end{array}$ & $1(1,89 \%)$ & $\begin{array}{c}7 \\
(13,21 \%)\end{array}$ & $\begin{array}{c}16 \\
(30,19 \%)\end{array}$ & $1(1,89 \%)$ & $4(7,55 \%)$ & $\begin{array}{c}19 \\
(35,85 \%)\end{array}$ \\
\hline
\end{tabular}




\begin{tabular}{|c|c|c|c|c|c|c|c|c|c|}
\hline 105 & $1(1,89 \%)$ & $\begin{array}{c}6 \\
(11,32 \%)\end{array}$ & $\begin{array}{c}11 \\
(20,75 \%)\end{array}$ & $0(0,00 \%)$ & $5(9,43 \%)$ & $\begin{array}{c}13 \\
(24,53 \%)\end{array}$ & $0(0,00 \%)$ & $2(3,77 \%)$ & $\begin{array}{c}16 \\
(30,19 \%)\end{array}$ \\
\hline 115 & $0(0,00 \%)$ & $4(7,55 \%)$ & $\begin{array}{c}11 \\
(20,75 \%)\end{array}$ & $0(0,00 \%)$ & $2(3,77 \%)$ & $\begin{array}{c}13 \\
(24,53 \%)\end{array}$ & $0(0,00 \%)$ & $0(0,00 \%)$ & 15 \\
$(28,30 \%)$
\end{tabular}

$\mathrm{T}=$ tempo em minutos, $\mathrm{A}$ = ausência de reação, $\mathrm{B}=$ reação moderada, $\mathrm{C}=$ reação intensa.

Quadro 4: Reações de nocicepção de exemplares de Dasyprocta azarae contidos pela associação cetamina, xilazina e atropina, à compressão de um dígito dos membros torácico e pélvico esquerdos, e da pele da região abdominal lateral esquerda, conforme o tempo após a injeção $(n=53)$

\begin{tabular}{|c|c|c|c|c|c|c|c|c|c|}
\hline \multirow[t]{2}{*}{$\mathbf{T}$} & \multicolumn{3}{|c|}{$\begin{array}{l}\text { Reação à compressão de um dígito } \\
\text { do membro torácico esquerdo }\end{array}$} & \multicolumn{3}{|c|}{$\begin{array}{l}\text { Reação à compressão de um dígito } \\
\text { do membro pélvico esquerdo }\end{array}$} & \multicolumn{3}{|c|}{$\begin{array}{l}\text { Reação à compressão da pele da } \\
\text { região abdominal lateral esquerda }\end{array}$} \\
\hline & A & B & C & A & B & $\mathrm{C}$ & $\mathbf{A}$ & B & $\mathrm{C}$ \\
\hline 5 & $\begin{array}{c}6 \\
(11,32 \%)\end{array}$ & $\begin{array}{c}13 \\
(24,53 \%)\end{array}$ & $\begin{array}{c}34 \\
(64,15 \%)\end{array}$ & $\begin{array}{c}8 \\
(15,09 \%)\end{array}$ & $\begin{array}{c}7 \\
(13,21 \%)\end{array}$ & $\begin{array}{c}38 \\
(71,70 \%)\end{array}$ & $\begin{array}{c}11 \\
(20,75 \%)\end{array}$ & $\begin{array}{c}13 \\
(24,53 \%)\end{array}$ & $\begin{array}{c}29 \\
(54,72 \%)\end{array}$ \\
\hline 10 & $\begin{array}{c}9 \\
(16,98 \%)\end{array}$ & $\begin{array}{c}13 \\
(24,53 \%)\end{array}$ & $\begin{array}{c}31 \\
(58,49 \%)\end{array}$ & $\begin{array}{c}16 \\
(30,19 \%)\end{array}$ & $\begin{array}{c}12 \\
(22,64 \%)\end{array}$ & $\begin{array}{c}25 \\
(47,17 \%)\end{array}$ & $\begin{array}{c}17 \\
(32,08 \%)\end{array}$ & $\begin{array}{c}12 \\
(22,64 \%)\end{array}$ & $\begin{array}{c}24 \\
(45,28 \%)\end{array}$ \\
\hline 15 & $\begin{array}{c}12 \\
(22,64 \%)\end{array}$ & $\begin{array}{c}12 \\
(22,64 \%)\end{array}$ & $\begin{array}{c}29 \\
(54,72 \%)\end{array}$ & $\begin{array}{c}20 \\
(37,74 \%)\end{array}$ & $\begin{array}{c}13 \\
(24,53 \%)\end{array}$ & $\begin{array}{c}20 \\
(37,74 \%)\end{array}$ & $\begin{array}{c}23 \\
(43,40 \%)\end{array}$ & $\begin{array}{c}13 \\
(24,53 \%)\end{array}$ & $\begin{array}{c}17 \\
(32,08 \%)\end{array}$ \\
\hline 25 & $\begin{array}{c}10 \\
(18,87 \%)\end{array}$ & $\begin{array}{c}17 \\
(32,08 \%)\end{array}$ & $\begin{array}{c}26 \\
(49,06 \%)\end{array}$ & $\begin{array}{c}20 \\
(37,74 \%)\end{array}$ & $\begin{array}{c}12 \\
(22,64 \%)\end{array}$ & $\begin{array}{c}21 \\
(39,62 \%)\end{array}$ & $\begin{array}{c}15 \\
(28,30 \%)\end{array}$ & $\begin{array}{c}20 \\
(37,74 \%)\end{array}$ & $\begin{array}{c}18 \\
(33,96 \%)\end{array}$ \\
\hline 35 & $\begin{array}{c}6 \\
(11,32 \%)\end{array}$ & $\begin{array}{c}16 \\
(30,19 \%)\end{array}$ & $\begin{array}{c}30 \\
(56,60 \%)\end{array}$ & $\begin{array}{c}18 \\
(33,96 \%)\end{array}$ & $\begin{array}{c}9 \\
(16,98 \%)\end{array}$ & $\begin{array}{c}26 \\
(49,06 \%)\end{array}$ & $\begin{array}{c}19 \\
(35,85 \%)\end{array}$ & $\begin{array}{c}12 \\
(22,64 \%)\end{array}$ & $\begin{array}{c}22 \\
(41,51 \%)\end{array}$ \\
\hline 45 & $\begin{array}{c}6 \\
(11,32 \%)\end{array}$ & $\begin{array}{c}13 \\
(24,53 \%)\end{array}$ & $\begin{array}{c}33 \\
(62,26 \%)\end{array}$ & $\begin{array}{c}15 \\
(28,30 \%)\end{array}$ & $\begin{array}{c}9 \\
(16,98 \%)\end{array}$ & $\begin{array}{c}28 \\
(52,83 \%)\end{array}$ & $\begin{array}{c}14 \\
(26,42 \%)\end{array}$ & $\begin{array}{c}20 \\
(37,74 \%)\end{array}$ & $\begin{array}{c}18 \\
(33,96 \%)\end{array}$ \\
\hline 55 & $3(5,66 \%)$ & $\begin{array}{c}11 \\
(20,75 \%)\end{array}$ & $\begin{array}{c}36 \\
(67,92 \%)\end{array}$ & $\begin{array}{c}6 \\
(11,32 \%)\end{array}$ & $\begin{array}{c}9 \\
(16,98 \%)\end{array}$ & $\begin{array}{c}35 \\
(66,04 \%)\end{array}$ & $\begin{array}{c}11 \\
(20,75 \%)\end{array}$ & $\begin{array}{c}13 \\
(24,53 \%)\end{array}$ & $\begin{array}{c}26 \\
(49,06 \%)\end{array}$ \\
\hline 65 & $2(3,77 \%)$ & $\begin{array}{c}11 \\
(20,75 \%)\end{array}$ & $\begin{array}{c}33 \\
(62,26 \%)\end{array}$ & $3(5,66 \%)$ & $\begin{array}{c}6 \\
(11,32 \%)\end{array}$ & $\begin{array}{c}37 \\
(69,81 \%)\end{array}$ & $\begin{array}{c}9 \\
(16,98 \%)\end{array}$ & $\begin{array}{c}13 \\
(24,53 \%)\end{array}$ & $\begin{array}{c}24 \\
(45,28 \%)\end{array}$ \\
\hline 75 & $2(3,77 \%)$ & $\begin{array}{c}10 \\
(18,87 \%)\end{array}$ & $\begin{array}{c}26 \\
(49,06 \%)\end{array}$ & $0(0,00 \%)$ & $5(9,43 \%)$ & $\begin{array}{c}33 \\
(62,26 \%)\end{array}$ & $\begin{array}{c}9 \\
(16,98 \%)\end{array}$ & $\begin{array}{c}9 \\
(16,98 \%)\end{array}$ & $\begin{array}{c}20 \\
(37,74 \%)\end{array}$ \\
\hline 85 & $2(3,77 \%)$ & $\begin{array}{c}6 \\
(11,32 \%)\end{array}$ & $\begin{array}{c}24 \\
(45,28 \%)\end{array}$ & $2(3,77 \%)$ & $3(5,66 \%)$ & $\begin{array}{c}26 \\
(49,06 \%)\end{array}$ & $3(5,66 \%)$ & $\begin{array}{c}10 \\
(18,87 \%)\end{array}$ & $\begin{array}{c}18 \\
(33,96 \%)\end{array}$ \\
\hline 95 & $0(0,00 \%)$ & $\begin{array}{c}6 \\
(11,32 \%)\end{array}$ & $\begin{array}{c}19 \\
(35,85 \%)\end{array}$ & $0(0,00 \%)$ & $2(3,77 \%)$ & $\begin{array}{c}22 \\
(41,51 \%)\end{array}$ & $2(3,77 \%)$ & $\begin{array}{c}8 \\
(15,09 \%)\end{array}$ & $\begin{array}{c}14 \\
(26,42 \%)\end{array}$ \\
\hline 105 & $0(0,00 \%)$ & $4(7,55 \%)$ & $\begin{array}{c}13 \\
(24,53 \%)\end{array}$ & $0(0,00 \%)$ & $2(3,77 \%)$ & $\begin{array}{c}16 \\
(30,19 \%)\end{array}$ & $1(1,89 \%)$ & $4(7,55 \%)$ & $\begin{array}{c}13 \\
(24,53 \%)\end{array}$ \\
\hline 115 & $0(0,00 \%)$ & $1(1,89 \%)$ & $\begin{array}{c}14 \\
(26,42 \%)\end{array}$ & $0(0,00 \%)$ & $0(0,00 \%)$ & $\begin{array}{c}15 \\
(28,30 \%)\end{array}$ & $1(1,89 \%)$ & $3(5,66 \%)$ & $\begin{array}{c}11 \\
(20,75 \%)\end{array}$ \\
\hline
\end{tabular}

$\mathrm{T}=$ tempo em minutos, $\mathrm{A}=$ ausência de reação, $\mathrm{B}=$ reação moderada, $\mathrm{C}=$ reação intensa.

Os dados referentes às reações de nocicepção dos animais à punção de uma veia safena lateral, realizada no vigésimo minuto após a injeção da associação de fármacos, encontram-se no Quadro 5. A análise de variância mostrou que houve diferença significativa $(\mathrm{p}<0,05)$ entre as reações de machos e fêmeas $(F=444,49, G L=52, p=0,001)$.

Quadro 5: Reações de nocicepção de exemplares de Dasyprocta azarae contidos pela associação cetamina, xilazina e atropina, à colheita de sangue por punção de uma veia safena lateral, realizada no vigésimo minuto após a injeção $(n=53)$

\begin{tabular}{|l|l|l|l|}
\hline Tipo de reação & Machos (\%) & Fêmeas (\%) & Total (\%) \\
\hline A & $29(54,72 \%)$ & $14(26,42 \%)$ & $43(81,13 \%)$ \\
\hline B & $2(3,77 \%)$ & $3(5,66 \%)$ & $5(9,43 \%)$ \\
\hline C & $2(3,77 \%)$ & $3(5,66 \%)$ & $5(9,43 \%)$ \\
\hline
\end{tabular}

$\mathrm{A}=$ ausência de reação, $\mathrm{B}=$ reação moderada, $\mathrm{C}=$ reação intensa.
Os dados referentes às reações de nocicepção dos animais à marcação $\mathrm{da}(\mathrm{s})$ orelha $(\mathrm{s})$, realizada no trigésimo minuto após a injeção da associação de fármacos, encontram-se no Quadro 6. A análise de variância mostrou que houve diferença significativa $(p<0,05)$ entre as reações de machos e fêmeas $(\mathrm{F}=835,27, \mathrm{GL}=51, \mathrm{p}=0,01)$. Neste caso, o número foi de 52 animais, pois um deles já havia sido marcado anteriormente. 
Quadro 6: Reações de nocicepção de exemplares de Dasyprocta azarae contidos pela associação cetamina, xilazina e atropina, à marcação da(s) orelha(s) por meio de cortes com tesoura cirúrgica, realizada no trigésimo minuto após a injeção $(\mathrm{n}=52)$

\begin{tabular}{|l|l|l|l|}
\hline $\begin{array}{c}\text { Tipo de } \\
\text { reação }\end{array}$ & Machos (\%) & Fêmeas (\%) & \multicolumn{1}{|c|}{ Total (\%) } \\
\hline $\mathrm{A}$ & $13(25,000 \%)$ & $4(7,69 \%)$ & $17(32,69 \%)$ \\
\hline $\mathrm{B}$ & $5(9,62 \%)$ & $2(3,85 \%)$ & $7(13,46 \%)$ \\
\hline $\mathrm{C}$ & $14(26,92 \%)$ & $14(26,92 \%)$ & $28(53,85 \%)$ \\
\hline
\end{tabular}

$\mathrm{A}=$ ausência de reação, $\mathrm{B}=$ reação moderada, $\mathrm{C}=$ reação intensa
Os dados referentes à qualidade do miorrelaxamento, conforme o tempo após a injeção da associação de fármacos encontram-se no Quadro 7. A reação do tipo "A” (excelente) foi mais frequente, chegando a $94,34 \%$ aos 15 minutos. A análise de variância mostrou que houve diferença significativa $(\mathrm{p}<0,05)$ entre as reações de machos e fêmeas $(\mathrm{F}=4,16$, $\mathrm{GL}=52, \mathrm{p}=0,04)$.

Quadro 7: Qualidade do miorrelaxamento observado em exemplares de Dasyprocta azarae contidos pela associação cetamina, xilazina e atropina $(\mathrm{n}=53)$

\begin{tabular}{|c|c|c|c|c|c|c|}
\hline \multirow{3}{*}{$\mathbf{T}$} & \multicolumn{6}{|c|}{ Tipo de reação } \\
\hline & \multicolumn{2}{|c|}{$\mathbf{A}$} & \multicolumn{2}{|c|}{ B } & \multicolumn{2}{|c|}{$\mathrm{C}$} \\
\hline & $\begin{array}{l}\text { Número de } \\
\text { animais }\end{array}$ & Frequência & $\begin{array}{l}\text { Número de } \\
\text { animais }\end{array}$ & Frequência & $\begin{array}{l}\text { Número de } \\
\text { animais }\end{array}$ & Frequência \\
\hline 5 & 46 & $86,79 \%$ & 4 & $7,55 \%$ & 3 & $5,66 \%$ \\
\hline 10 & 48 & $90,57 \%$ & 3 & $5,66 \%$ & 2 & $3,77 \%$ \\
\hline 15 & 50 & $94,34 \%$ & 3 & $5,66 \%$ & 0 & $0,00 \%$ \\
\hline 25 & 49 & $92,45 \%$ & 4 & $7,55 \%$ & 0 & $0,00 \%$ \\
\hline 35 & 47 & $88,68 \%$ & 6 & $11,32 \%$ & 0 & $0,00 \%$ \\
\hline 45 & 47 & $88,68 \%$ & 4 & $7,55 \%$ & 1 & $1,89 \%$ \\
\hline 55 & 38 & $71,70 \%$ & 8 & $15,09 \%$ & 4 & $7,55 \%$ \\
\hline 65 & 32 & $60,38 \%$ & 5 & $9,43 \%$ & 9 & $16,98 \%$ \\
\hline 75 & 27 & $50,94 \%$ & 6 & $11,32 \%$ & 5 & $9,43 \%$ \\
\hline 85 & 22 & $41,51 \%$ & 5 & $9,43 \%$ & 4 & $7,55 \%$ \\
\hline 95 & 16 & $30,19 \%$ & 6 & $11,32 \%$ & 2 & $3,77 \%$ \\
\hline 105 & 10 & $18,87 \%$ & 5 & $9,43 \%$ & 3 & $5,66 \%$ \\
\hline 115 & 10 & $18,87 \%$ & 2 & $3,77 \%$ & 3 & $5,66 \%$ \\
\hline
\end{tabular}

$\mathrm{T}=$ tempo em minutos, $\mathrm{A}=$ miorrelaxamento excelente, $\mathrm{B}=$ miorrelaxamento bom, $\mathrm{C}=$ miorrelaxamento ruim

\section{Duração da contenção farmacológica}

O Quadro 5 resume os dados de frequência (número de animais) referente ao tempo do início do despertar, da impossibilidade de manipulação sem riscos, do retorno da reação postural de endireitamento e do retorno à ambulação normal. Os tempos médios e os dados separados para machos e fêmeas de cada um desses parâmetros avaliados são apresentados nos Quadros 9 a 12.

Quadro 8: Frequências (n) segundo o tempo do início do despertar, momento da impossibilidade de manipulação sem riscos, retorno da reação postural de endireitamento e retorno à ambulação normal de 53 exemplares de Dasyprocta azarae contidos pela associação cetamina, xilazina e atropina

\begin{tabular}{|l|c|c|c|c|c|c|c|c|}
\hline \multirow{2}{*}{$\begin{array}{c}\text { Tempo em } \\
\text { minutos }\end{array}$} & \multicolumn{2}{|c|}{ Início do despertar } & \multicolumn{2}{|c|}{$\begin{array}{c}\text { Momento da impossibili- } \\
\text { dade de manipulação }\end{array}$} & $\begin{array}{c}\text { Retorno da reação postu- } \\
\text { ral de endireitamento }\end{array}$ & \multicolumn{2}{|c|}{$\begin{array}{c}\text { Retorno à ambulação } \\
\text { normal }\end{array}$} \\
\cline { 2 - 10 } & (n) & Frequência & (n) & Frequência & (n) & Frequência & (n) & Frequência \\
\hline 40 A 50 & 7 & $13,21 \%$ & 2 & $3,77 \%$ & - & - & - & - \\
\hline 51 A 60 & 4 & $7,55 \%$ & 2 & $3,77 \%$ & 1 & $1,89 \%$ & - & - \\
\hline 61 A 70 & 11 & $20,75 \%$ & 7 & $13,21 \%$ & - & - & - & - \\
\hline 71 A 80 & 8 & $15,09 \%$ & 8 & $15,09 \%$ & - & - & - & - \\
\hline 81 A 90 & 7 & $13,21 \%$ & 8 & $15,09 \%$ & 6 & $11,32 \%$ & - & - \\
\hline 901A 100 & 5 & $9,43 \%$ & 5 & $9,43 \%$ & 7 & $13,21 \%$ & - & - \\
\hline 101 A 110 & 4 & $7,55 \%$ & 6 & $11,32 \%$ & 4 & $7,55 \%$ & 3 & $5,66 \%$ \\
\hline 111 A 120 & 7 & $13,21 \%$ & 4 & $7,55 \%$ & 8 & $15,09 \%$ & 4 & $7,55 \%$ \\
\hline 121 A 130 & - & - & 11 & $20,75 \%$ & 7 & $13,21 \%$ & - & - \\
\hline
\end{tabular}




\begin{tabular}{|l|c|c|c|c|c|c|c|c|}
\hline 131 A 140 & - & - & - & - & 5 & $9,43 \%$ & 8 & $15,09 \%$ \\
\hline 141 A 150 & - & - & - & - & 4 & $7,55 \%$ & 4 & $7,55 \%$ \\
\hline 151 A 160 & - & - & - & - & 2 & $3,77 \%$ & 8 & $15,09 \%$ \\
\hline 161 A 170 & - & - & - & - & 4 & $7,55 \%$ & 5 & $9,43 \%$ \\
\hline 171 A 180 & - & - & - & - & 2 & $3,77 \%$ & 7 & $13,21 \%$ \\
\hline 181 A 190 & - & - & - & - & 1 & $1,89 \%$ & 2 & $3,77 \%$ \\
\hline 191 A 200 & - & - & - & - & 1 & $1,89 \%$ & 2 & $3,77 \%$ \\
\hline 201 A 210 & - & - & - & - & 1 & $1,89 \%$ & 3 & $5,66 \%$ \\
\hline 211 A 220 & - & - & - & - & - & - & 3 & $5,66 \%$ \\
\hline 221 A 230 & - & - & - & - & - & - & - & - \\
\hline 231 A 240 & - & - & - & - & - & - & 2 & $3,77 \%$ \\
\hline 241 A 250 & - & - & - & - & - & - & - & - \\
\hline 251 A 260 & - & - & - & - & - & - & - & - \\
\hline 261 A 270 & - & - & - & - & - & - & - & - \\
\hline 271 A 280 & - & - & - & - & - & - & 1 & $1,89 \%$ \\
\hline TOTAL & 53 & 100 & 53 & 100 & 53 & 100 & 53 & 100 \\
\hline
\end{tabular}

Quadro 9: Período médio (em minutos) para início do despertar de machos e fêmeas de Dasyprocta azarae submetidos à contenção farmacológica pela associação cetamina, xilazina e atropina $(\mathrm{n}=53)$

\begin{tabular}{|l|l|l|}
\hline \multicolumn{1}{|c|}{ Sexo } & $\begin{array}{c}\text { Tempo em minutos } \\
\text { (média } \pm \text { desvio } \\
\text { padrão) }\end{array}$ & $\begin{array}{c}\text { Número de animais } \\
(\%)\end{array}$ \\
\hline Masculino & $78,54 \pm 20,69$ & $33(62,27 \%)$ \\
\hline Feminino & $80,40 \pm 27,11$ & $20(37,73 \%)$ \\
\hline Ambos & $79,24 \pm 23,08$ & $53(100,00 \%)$ \\
\hline
\end{tabular}

Quadro 10: Período médio do momento (em minutos) da impossibilidade de manipulação de machos e fêmeas de Dasyprocta azarae contidos pela associação cetamina, xilazina e atropina $(n=53)$

\begin{tabular}{|l|l|l|}
\hline \multicolumn{1}{|c|}{ Sexo } & $\begin{array}{c}\text { Tempo em minutos } \\
\text { (média } \pm \text { desvio } \\
\text { padrão) }\end{array}$ & $\begin{array}{c}\text { Número de animais } \\
(\%)\end{array}$ \\
\hline Masculino & $92,45 \pm 20,86$ & $33(62,27 \%)$ \\
\hline Feminino & $92,90 \pm 27,24$ & $20(37,73 \%)$ \\
\hline Ambos & $92,62 \pm 23,21$ & $53(100,00 \%)$ \\
\hline
\end{tabular}

Quadro 11: Período médio do momento do despertar (em minutos) de machos e fêmeas de Dasyprocta azarae contidos pela associação cetamina, xilazina e atropina $(n=53)$

\begin{tabular}{|l|l|l|}
\hline \multicolumn{1}{|c|}{ Sexo } & $\begin{array}{c}\text { Tempo em minutos } \\
\text { (média } \pm \text { desvio } \\
\text { padrão) }\end{array}$ & $\begin{array}{c}\text { Número de animais } \\
(\%)\end{array}$ \\
\hline Masculino & $125,03 \pm 31,66$ & $33(62,27 \%)$ \\
\hline Feminino & $126,15 \pm 34,06$ & $20(37,73 \%)$ \\
\hline Ambos & $125,45 \pm 32,27$ & $53(100,00 \%)$ \\
\hline
\end{tabular}

Quadro 12: Período médio do momento do retorno à ambulação normal de machos e fêmeas de Dasyprocta azarae contidos pela associação cetamina, xilazina e atropina $(n=53)$

\begin{tabular}{|l|l|l|}
\hline \multicolumn{1}{|c|}{ Sexo } & $\begin{array}{c}\text { Tempo em minutos } \\
\text { (média } \pm \text { desvio } \\
\text { padrão) }\end{array}$ & $\begin{array}{c}\text { Número de animais } \\
(\%)\end{array}$ \\
\hline Masculino & $162,51 \pm 32,01$ & $33(62,26 \%)$ \\
\hline Feminino & $168,95 \pm 44,98$ & $20(37,73 \%)$ \\
\hline Ambos & $164,94 \pm 37,14$ & $53(100,00 \%)$ \\
\hline
\end{tabular}

Os fenômenos definidos como característicos do início do despertar ocorreram entre 40 e 120 minutos após a injeção da associação de fármacos, com média de 79,24 23,08 minutos. A análise de variância do período em que ocorreu o início do despertar demonstrou que não houve diferença significativa $(p>0,05)$ entre o comportamento de machos e fêmeas $(\mathrm{F}=0,0789, \mathrm{GL}=52, \mathrm{p}=0,779)$. O momento em que a manipulação sem riscos dos animais tornou-se impossível variou de 44 a 124 minutos após a injeção da associação de fármacos, com média de 92,62 $\pm 23,21$ minutos.

A análise de variância do período em que a manipulação sem riscos tornou-se impossível demonstrou que não houve diferença significativa $(\mathrm{p}>0,05)$ entre o comportamento de machos e fêmeas $(\mathrm{F}=0,004, \mathrm{GL}=52, \mathrm{p}=0,946)$. O tempo em que os animais permaneceram contidos variou de 52 a 209 minutos após a injeção da associação de fármacos, com média de $125,45 \pm 32,27$. A análise de variância do período em que os animais recuperaram a reação postural de endireitamento demonstrou que não houve diferença significativa $(\mathrm{p}>0,05)$ entre o comportamento de machos e fêmeas $(\mathrm{F}=0,015, \mathrm{GL}=52$, $\mathrm{p}=0,903)$. O momento em que se observou o retorno da capacidade de ambulação normal variou de 105 a 277 minutos após a injeção da associação de fármacos, com média de $164,94 \pm 37,14$ minutos.

A análise de variância do período em que os animais retornaram à ambulação normal demonstrou que não houve diferença significativa $(p>0,05)$ entre o comportamento de machos e fêmeas $(\mathrm{F}=0.369, \mathrm{GL}=52, \mathrm{p}=0,546)$. Os valores obtidos no teste de Bartlett para esses parâmetros $\left(\mathrm{X}^{2}=1,718\right.$, 
$\mathrm{X}^{2}=1,759, \mathrm{X}^{2}=0,126,2,81$, respectivamente) possibilitam afirmar que as variâncias foram homogêneas.

\section{Discussão}

Este estudo foi realizado em condições reais de trabalho relacionado à rotina de parques zoológicos e criadouros de animais selvagens, como captura, contenção, biometria, determinação de sexo, marcação, exame físico, colheita de fluidos orgânicos e realização de procedimentos médicos e cirúrgicos.

O número de animais utilizados, ainda que relativamente pequeno, é bastante significativo devido à extrema dificuldade de obtenção de exemplares puros de Dasyprocta azarae para qualquer tipo de experimento. Muitos zoológicos brasileiros mantêm plantéis, de cutias, mas geralmente pequenos e com intensa hibridação devida a cruzamentos interespecíficos. Ademais, o grupo de animais estudados é uma amostra bastante representativa do que se encontraria em populações selvagens, já que os animais utilizados apresentam exatamente o mesmo padrão fenotípico descrito na literatura para D. azarae (MARGARIDO, 1989; BORGES, 1989; EMMONS, 1990).

O uso do saco de pano para contenção física inicial dos animais demonstrou ser equipamento de fundamental importância no manejo de Dasyprocta azarae ao restringir os movimentos dos animais e permitir sua pesagem e imobilização parcial previamente à injeção da associação de fármacos. Este procedimento contribuiu significativamente para reduzir os riscos do estresse e, consequentemente, os riscos anestésicos.

O cloridrato de cetamina é o fármaco mais utilizado na contenção de animais selvagens, sendo que a ordem Rodentia não foge à esta regra. Esse fármaco apresenta ampla variação de efeitos nos diversos grupos taxonômicos, e até mesmo entre os vários gêneros e espécies de uma mesma família. Existe ampla variabilidade também no que diz respeito aos protocolos posológicos empregados, sendo propostas, para roedores, doses de 5,0 a 120,0mg/kg (STUNKARD; MILLER, 1974, BECK, 1976; BACHER et al., 1976; STOSKOPF, 1979; SEDGWICK, 1980; GENEVOIS et al., 1984; CLARK; OLFERT, 1986; FRASE; VAN VUREN, 1989; SCHUCHMAN, 1989; PACHALY, 1991; 1992; 1996). Seu uso isolado não é recomendável, pois pode provocar diversos efeitos indesejáveis, como catalepsia, episódios convulsivos, sialorreia e certas reações psicomotoras durante a recuperação anestésica. Para roedores selvagens, a sialorreia não chega a representar um problema, porém a ocorrência de processos convulsivos deve ser evitada para reduzir os riscos anestésicos e facilitar a manipulação dos animais (BECK, 1976; SAWYER et al., 1977; WHITE et al., 1982; WRIGHT, 1982; MEYER-JONES et al., 1983; FOWLER, 1986; PLUMB, 1991; MUIR; HUBBEL, 1995).

Em função dos efeitos indesejáveis do cloridrato de cetamina, diversos autores preconizam a associação a outros fármacos, como o sulfato de atropina e agonistas de receptores adrenérgicos $\alpha_{2}$ (STUNKARD; MILLER, 1974; NAVARRO; FRIEDMAN, 1975; BACHER et al., 1976; BECK, 1976; CULLEN; JONES, 1977; KAPLAN, 1979; SEDGWICK, 1979; 1980; WRIGHT, 1982; MEYER-JONES et al., 1983; WALLACH; BOEVER, 1983; FIALHO, 1985; FOWLER, 1986; LÉONARD, 1986; ALLERT; ADAMS, 1987; THUR-
MON; BENSON, 1987; WHITE; FIELD, 1987; WIXSON et al., 1987; MASSONE, 1988; MANDSAGER; RAFFE, 1989; SCHUCHMAN, 1989; BELANT, 1991; PLUMB, 1991; BELANT, 1991; HASKINS, 1992; KLIDE, 1992; JALANKA, 1993; ARNEMO et al., 1994; BÓ et al., 1994; FERRERAS et al., 1994; GARNER; ADDISON, 1994; HOLZ et al., 1994; ARNEMO; SOLI, 1995; BAILEY et al., 1995; BELTRÁN; TEWES, 1995; MATTHEWS et al., 1995; MUIR; HUBBEL, 1995; BELANT, 1996; HEARD et al., 1996; NICHOLLS et al., 1996; OSOFSKY et al., 1996).

A associação de fármacos empregada e o uso da extrapolação alométrica para o cálculo de suas doses foram as razões para a eficiência e da qualidade da contenção farmacológica ter sido considerada excelente em 100\% dos animais no presente experimento. Esse método de cálculo para a definição das doses dos fármacos provou ser extremamente seguro, pois não se observaram acidentes ou mortes relacionados aos fármacos ou suas doses. Escolheu-se o cão doméstico como animal modelo para o cálculo das doses dos fármacos testadas porque para ele as doses já haviam sido previamente estabelecidas mediante estudos farmacocinéticos e farmacodinâmicos tradicionais. Essa escolha provou-se acertada haja vista os resultados obtidos.

O método empregado para a administração da associação de fármacos mostrou-se simples, prático e plenamente eficaz. Tanto a mistura dos três fármacos em uma mesma seringa quanto a injeção pela via intramuscular valorizaram o conceito de que em procedimentos de anestesia de campo devem ser priorizadas a praticidade e a facilidade na administração dos fármacos (SEDGWICK, 1979). A via intramuscular permitiu a administração rápida e segura da associação de fármacos, coincidindo com os dados de Beck (1976) e Sedgwick (1979, 1988), segundo os quais esta é a via mais indicada para animais selvagens. Stoskopf (1979), Sedgwick (1980), Wallach e Boever (1983), Genevois et al. (1984), Clark e Olfert (1986), White e Field (1987), Frase e Van Vuren (1989) e Pachaly (1992b) consideram-na a mais adequada para roedores selvagens em situações de trabalho de campo.

A perda da reação postural de endireitamento, ou seja, da capacidade de recuperar a posição quadrupedal após o decúbito foi o principal indicativo da indução do estado de contenção farmacológica. Esta indução foi rápida, como geralmente ocorre quando da utilização de agentes dissociativos (BECK, 1976; WRIGHT, 1982; FOWLER, 1986). O tempo para perda da reação postural de endireitamento foi significativamente menor em machos. A explicação para tal diferença reside, dentre outros fatores, no fato da reação dos machos estar relacionada a sua atividade metabólica maior que a das fêmeas, possibilitando absorção e efeito mais rápidos dos fármacos. Dos hormônios androgênios naturais produzidos pelos mamíferos, a testosterona é o mais importante (McDONALD, 1992). A testosterona atua sobre o metabolismo como agente anabólico, bem como é responsável pelo comportamento mais agressivo e a maior atividade física dos machos (HADLEY, 1988; McDONALD, 1992; WILSON, 1995).

A frequência cardíaca variou consideravelmente durante o experimento, e de maneira similar para machos e fêmeas. Há que se considerar que cada uma dos fármacos componentes da associação apresenta efeitos sobre o aparelho cardiovascular. Tais efeitos muitas vezes são antagônicos, em função do próprio interesse de que a associação proporcione 
segurança aos animais. Assim, o efeito estimulante sobre o sistema circulatório observado na utilização isolada do cloridrato de cetamina, ocasionando taquicardia e hipertensão arterial (WRIGHT, 1982, MASSONE,1988), é em parte bloqueado pelo cloridrato de xilazina, que apresenta potente ação hipotensora e bradicardizante (SOMA, 1971; SAWYER et al., 1977; SEDGWICK, 1979; WRIGHT, 1982; MEYER JONES et al., 1983; FIALHO, 1985; FOWLER, 1986; MANDSAGER; RAFFE, 1989). O sulfato de atropina apresenta efeito contrário a tais ações do cloridrato de xilazina, sendo neste caso empregado para evitar os riscos da bradicardia e da hipotensão, conforme Soma (1971), Soma e Penney (1975), Wright (1982) e Massone (1988). No presente experimento, a elevada frequência inicial pode ser creditada ao estresse devido aos procedimentos de captura, pesagem e administração da associação de fármacos, bem como a uma ação inicial mais intensa do sulfato de atropina. A diminuição progressiva observada a seguir é compatível com uma estabilização da função circulatória, estando a ação bradicardizante do cloridrato de xilazina contrabalançada pelos efeitos do cloridrato de cetamina e do sulfato de atropina. A elevação observada ao final é indicativa da recuperação dos animais, em função da biotransformação e eliminação dos fármacos.

A frequência respiratória, que esteve mais elevada no início, caiu progressivamente durante a vigência do estado de contenção. Essas frequências foram significativamente maiores para machos do que para fêmeas. $(83,84 \pm 26,54)$ que as fêmeas $(75,24 \pm 32,48)$. A elevada frequência inicial pode ser creditada ao estresse devido aos procedimentos de captura, pesagem e administração da associação de fármacos. A queda progressiva observada a seguir é compatível com o estado de contenção farmacológica. A maior frequência respiratória observada nos machos pode ser devida à ação da testosterona sobre sua atividade orgânica, que tende a ser maior que a das fêmeas (HADLEY, 1988; McDONALD, 1992; WILSON, 1995).

A temperatura retal média dos animais decresceu progressivamente durante a contenção farmacológica. A temperatura média das fêmeas $\left(36,77 \pm 2,03^{\circ} \mathrm{C}\right)$ foi alguns décimos maior que a dos machos $\left(36,12 \pm 2,03^{\circ} \mathrm{C}\right)$. Embora pequena essa diferença foi significativamente diferente. Para as fêmeas, ocorreram dois momentos, aos 75 e aos 115 minutos, em que houve um aumento de aproximadamente $1,2^{\circ} \mathrm{C}$ em relação aos machos. Não se encontrou uma explicação plenamente adequada para tal diferença. Em termos hipotéticos, é possível imaginar que a maior atividade metabólica dos machos, devida à ação da testosterona, fez com que o efeito da contenção farmacológica sobre o centro nervoso termo-regulador, localizado no hipotálamo, fosse mais intenso. Contudo, a carência de informações a este respeito, e a impossibilidade de aferição dos dados referentes à temperatura retal de machos e fêmeas, previamente à contenção farmacológica, ainda não permitem a comprovação desta hipótese. Quanto à expressiva diminuição progressiva observada na temperatura retal, tanto de machos quanto de fêmeas, é importante mencionar que a maioria dos anestésicos causa hipotermia por inibição de mecanismos termo-reguladores centrais e periféricos (HALL, 1978; WIXSON et al., 1987). Obviamente, a imobilidade inibe diretamente a termo-regulação ao inibir o tremor. Devido a seu pequeno tamanho e alta taxa metabólica, os roedores são particularmente suscetíveis à perda de calor para o ambiente durante anestesia, e é possível que a perda da homeostase térmica possa ser uma importante causa da alta mortalidade frequentemente relatada após a anestesia de roedores de laboratório (WIXSON et al., 1987). Na presente pesquisa, apesar da severa hipotermia observada nos animais, durante o período de monitorização anestesiológica, não se observou mortalidade, e a recuperação após a contenção farmacológica ocorreu sem quaisquer percalços. Isto sugere que devam ser conduzidos estudos especialmente voltados à temperatura central de cutias, e suas variações. Nenhuma das cutias, observadas até recobrarem a capacidade de ambulação normal, apresentou tremores. Quanto à causa preponderante da hipotermia observada nas cutias, é possível supor que tenha sido a depressão provocada pelo cloridrato de cetamina sobre o centro nervoso de termo-regulação, mencionada por Wright (1982), Lin et al. (1978) e Wixson et al., 1987.

Os dados referentes a temperatura retal, frequência cardíaca frequência respiratória, tanto neste experimento como em outros em que animais selvagens necessitem ser sedados ou anestesiados para que se possa realizar a coleta de dados biológicos, devem ser interpretados de modo judicioso. Procedimentos de investigação biomédica que dependam de captura e contenção prévias sempre estarão sujeitos às interferências do estresse. O estresse "agudo", relacionado à liberação de catecolaminas durante a realização de tais procedimentos, é capaz de alterar substancialmente os dados coletados. Atua da mesma forma o estresse "crônico", devido ao cativeiro prolongado, sob condições inadequadas de manejo, em que ocorre hipercortisolemia crônica. O uso da palavra "normal", portanto, está condicionado às necessidades de emprego e interpretação que se dá a tais valores. Para o presente experimento, considerou-se o tempo decorrido entre a captura e a administração da associação de fármacos como situação estressante e potencialmente capaz de induzir alterações nos dados vitais de temperatura retal, frequência cardíaca e frequência respiratória basais. A importância do estabelecimento de valores de referência para animais selvagens em suas condições ambientais naturais deve, evidentemente, ser enfatizada. Mas, dados obtidos durante o repouso e na ausência de qualquer fator que gere estresse em Dasyprocta azarae só seriam possíveis através de estudos com monitorização remota, e até hoje nunca foram feitos. A inexistência de referências bibliográficas sobre aqueles parâmetros e a impossibilidade de sua aferição previamente à administração da associação de fármacos impedem que se estabeleçam comparações e dificultam uma discussão mais abrangente de tais resultados.

É importante notar que os dados referentes a temperatura retal, frequência cardíaca frequência respiratória em D. azarae colhidos durante este experimento são os únicos disponíveis para a espécie. Exatamente por isso tornam-se indispensáveis para o acompanhamento médico de outros animais submetidos a procedimentos semelhantes de contenção farmacológica e podem ser considerados como "normais" para os indivíduos da amostra populacional estudada.

A sialorreia é um efeito frequente da utilização do cloridrato de cetamina em roedores (STUNKARD; MILLER, 1974; BECK 1976; WHITE; FIELD, 1987; PACHALY, 1992), mas no presente estudo, entretanto, não se observou tal complicação, ou mesmo hipersecreção brônquica em nenhum animal, seguramente devido à ação terapêutica do sulfato de atropina. 
Todos os animais mantiveram os olhos abertos e dilatação pupilar fixa no decorrer do processo de contenção farmacológica, uma manifestação comum devido, respectivamente, à ação do cloridrato de cetamina e sulfato de atropia em animais domésticos (SOMA 1975; MEYER-JONES et al., 1983) e em Cuniculus (Agouti) paca (PACHALY, 1992b). Com a finalidade de evitar a dessecação das córneas durante a contenção farmacológica, foi realizada a irrigação dos olhos dos animais com solução fisiológica de cloreto de sódio a $0,9 \%$, a cada vez que se realizou o exame anestesiológico.

A avaliação da nocicepção e do miorrelaxamento atribuindo-se a conceituação "excelente", "bom" e "ruim" foi feita da maneira menos subjetiva possível, estabelecendo-se pontos específicos que deveriam estar presentes ou ausentes para atribuição dos conceitos. O método empregado para avaliação daqueles parâmetros mostrou-se simples e eficaz, bem como a sua interpretação, tendo sido baseado em estudos para Cuniculus (Agouti) paca (PACHALY, 1992), com alterações destinadas a possibilitar maior exatidão. Após a avaliação preliminar das reações aos testes de nocicepção, foi possível definir a qual dos testes um maior número de animais reagiu com manifestações de dor, durante maior espaço de tempo. Este critério mostrou que a avaliação da reação ao pinçamento de um dígito do membro torácico esquerdo, avaliada aos dez, 15, 25 e 35 minutos revelou-se o melhor método para interpretação judiciosa da nocicepção. Em consequência este parâmetro, juntamente com a reação à punção venosa para colheita de sangue, feita aos 29 minutos e à marcação $\mathrm{da}(\mathrm{s})$ orelha(s) feita aos 30 minutos foram eleitos como padrão para avaliação da analgesia obtida durante a contenção farmacológica. A escolha desses parâmetros e dos tempos de avaliação justifica-se em função do fato de que a grande maioria dos procedimentos médicos e de manejo realizados rotineiramente com exemplares de D. azarae terem duração menor que 20 minutos, e se iniciarem alguns minutos depois de observada a perda da reação postural de endireitamento. Além disso, procedimentos de marcação e colheita de sangue são processos para os quais comumente se indica a contenção farmacológica.

\section{Conclusões}

Em termos gerais, mais de $50 \%$ dos animais exibiram analgesia considerada "ruim" (C) aos 10 e os 35 minutos. Tal fato permite concluir que o protocolo estudado não é recomendado como método único para contenção de exemplares de Dasyprocta azarae que necessitem ser submetidos a procedimentos muito dolorosos, como grandes cirurgias, por exemplo.

No que tange à reação à punção de uma veia safena lateral para colheita de sangue, $81,13 \%$ apresentaram analgesia "excelente" (A) e 9,43\% apresentaram analgesia "boa" (B). As mesmas justificativas apresentadas para a avaliação da sensibilidade são válidas para a avaliação da qualidade da contenção. Em termos gerais, contenção farmacológica "excelente" (A) foi observada em cerca de 90,00\% dos casos, e "boa" (B) em mais de $5,00 \%$ dos casos.

Tendo em vista esses resultados, pode-se afirmar que o método proposto aqui é indicado para a contenção farmacológica de exemplares de D. azarae que necessitem ser submetidos a procedimentos indolores, como a realização de exame físico, biometria e determinação de sexo, ou procedimentos medianamente dolorosos ou incômodos, como colheita de san- gue, colheita de fezes diretamente do reto, colheita de urina por compressão ou por punção vesical, realização de curativos e aplicação de bandagens.

Todos os animais $(100,00 \%)$ apresentaram recuperação satisfatória, apesar de prolongada, não se observando reações de despertar ou óbitos. O método estudado tem características de segurança e eficiência que o tornam viável para a contenção farmacológica de D. azarae, tanto em parques zoológicos e criadouros, quanto em trabalhos de campo. É muito importante, entretanto, frisar a necessidade de acompanhamento clínico de cada animal, em ambiente tranquilo e silencioso, até que recobre plenamente a capacidade ambulatória.

O exame anestesiológico proposto por Pachaly (1998) foi validado neste estudo, mostrando-se eficiente para avaliação de miorrelaxamento e nocicepção, permitindo qualificar a contenção farmacológica.

\section{Referências}

ALLERT, J. A.; ADAMS, H. R. Pharmacologic considerations in selection of tranquilizers, sedatives and muscle relaxant drugs used in inducing animal restraint. Journal of the American Veterinay Medical Association, v. 191, n. 10, p. 1241-1244, 1987.

ARNEMO J. M. et al. Immobilization of captive pine martens (Martes martes) with medetomidine-ketamine and reversal with atipamezole. Journal of Zoo and Wildlife Medicine, v. 25, n. 4, p. 548-554, 1994.

ARNEMO, J. M.; SOLI, N. E. Chemical immobilization of free-ranging european hedgehogs (Erinaceus europaeus).

Journal of Zoo and Wildlife Medicine, v. 26, n. 2, p. 246$251,1995$.

BACHER, J. D. et al. An evaluation of sedatives and anesthetics in the agouti (Dasyprocta sp.). Laboratory Animal Science, v. 26, n. 2, p. 195-198, 1976.

BAILEY, T. A. et al. Reversible anesthesia of the blue duiker (Cephalophus monticola) with medetomidine and ketamine. Journal of Zoo and Wildlife Medicine, v. 26, n. 2, p. 237-239, 1995.

BECK, C. C. Vetalar (ketamine $\mathrm{HCl}$ ): A unique cataleptoid anesthetic agent for multispecies usage. Journal of Zoo Animal Medicine, v. 7, n. 3, p. 11-38, 1976.

BELANT, J. L. Immobilization of fishers (Martes pennanti) with ketamine hydrochloride and xylazine hydrochloride. Journal of Wildlife Diseases, v. 27, n. 2, p. 328-330, 1991.

BELANT, J. L. Immobilization of muskrats (Ondatra zibethicus) with ketamine and xylazine. Journal of Wildlife Diseases, v. 32, n. 1, p.152-155, 1996.

BELTRÁN, J. F.; TEWES, M. E. Immobilization of ocelots and bobcats with ketamine hydrochloride and xylazine hydrochloride. Journal of Wildlife Diseases, v. 31, n.1, p. 43-48, 1995. 
BÓ, R. F. et al. Immobilization of coypus (Myocastor coypus) with ketamine hydrocloride and xylazine hydrochloride. Journal of Wildlife Diseases, v. 30, n. 4, p. 596-598, 1994.

BORGES, C. R. S. Composição mastofaunística do Parque Estadual de Vila Velha, Ponta Grossa, Paraná, Brasil. 1989. 86 f. Dissertação (Mestrado em Zoologia) - Setor de Ciências Biológicas, Universidade Federal do Paraná, Curitiba, 1989.

CHRISMAN, C. L. Limb paralysis. In: AIELLO, S. E. The Merck veterinary manual. 8 . ed. Philadelphia: National Publishing, 1998. p. 943.

CLARK, J. D.; OLFERT, E. D. Rodents (Rodentia). In: FOWLER, M. E. Zoo and wild animal medicine. 2. ed. Philadelphia: W. B. Saunders, 1986. p. 728-737.

CULLEN, L. K.; JONES, R. S. Clinical observations on xylazine/ketamine anaesthesia in the cat. Veterinary Record, v.101, n. 6, p.115-116, 1977.

DOMINO, E. F. et al. Pharmacologic effects of CI-581, a new dissociative anesthetic in man. Clinical Pharmacology and Therapeutics, v. 6, p. 279-291, 1965.

EMMONS, L. H. Neotropical rainforest mammals: a field guide. Chicago: The University of Chicago Press, 1990. p.166-210.

FERRERAS, P. et al. Immobilization of the endangered iberian lynx with xylazine and ketamine hydrochloride. Journal of wildlife diseases, v. 30, n. 1, p. 65-68, 1994.

FIALHO, S. A. G. Anestesiologia veterinária. São Paulo: Nobel, 1985. 234 p.

FOWLER, M. E. Restraint. In: Zoo and wild animal medicine. 2. ed. Philadelphia: W. B. Saunders, 1986. p. 38-50.

FRASE, B. A.; VAN VUREN, D. Techniques for immobilizing and bleeding marmots and woodrats. Journal of Wildlife Diseases, v. 25, n. 3, p. 444-445, 1989.

GARNER, D. L.; ADDISON, E. M. Postpartum immobilization of adult female moose using xylazine, ketamine and yohimbine hydrochloride. Journal of Wildlife Diseases, v. 30, n. 1, p. 123-125, 1994.

GENEVOIS, J. P. et al. L'anesthésie des espèces insolites en pratique vétérinaire courante: Note 3. L`anesthésie du lapin et des rongeurs. Révue de Médecine Véterinaire, v. 135, n. 5, p. 273-279, 1984.

HADLEY, M. E. Endocrinology. Englewood Cliffs: Prentice Hall, 1988. p. 414-418.

HARTSFIELD, S. M. Advantages and guidelines for using ketamine for induction of anesthesia. Veterinary Clinics of North America - Small Animal Practice, v. 22, n. 2, p. 266-267, 1992.

HASKINS, S. C. Injectable anesthetics. Veterinary Clinics of North America - Small Animal Practice, v. 22, n. 2, p. 245-260, 1992.

HEARD, D. J. et al. Ketamine and ketamine: xylazine $\mathrm{ED}_{50}$ for short term immobilization of the island flying fox (Pteropus hypomelanus). Journal of Zoo and Wildlife Medicine, v. 27, n. 1, p. 44-48, 1996.

HOLZ, P. et al. Effects of atropine on medetomidine/ ketamine immobilization in the gray wolf (Canis lupus). Journal of Zoo and Wildlife Medicine, v. 25, n. 2, p. 209213,1994

HONACKI, J. H. et al. Mammal species of the world. Lawrence: Allen Press and the Association of Systematic Collections, 1982. 694 p.

JALANKA, H. H. New $\alpha_{2}$-adrenoceptor agonists and antagonists. In: FOWLER, M. E. Zoo and wild animal medicine: current therapy. 3. ed. Philadelphia: W. B. Saunders, 1993. p. 477-481.

KAPLAN, B. A practitioner's report on the use of ketamine and xylazine with or without thiamylal for general anesthesia in dogs. Veterinary Medicine - Small Animal Clinician, v. 74, n. 9, p. 1267-1268, 1979.

KIRKWOOD, J. K. Influence of body size in animals on health and disease. Veterinary Record, v. 113, n. 13, p. 287-290, 1983.

KLIDE, A. M. Precautions when using alpha-2 agonists as anesthetics or anesthetic adjuvants. Veterinary Clinics of North America - Small Animal Practice, v. 22, n. 2, p. 294-295, 1992.

LANGE, R. B. Criação e relocação de cutias Dasyprocta azarae Lichtenstein, 1823 (Dasyproctidae, Mammalia) em área verde urbana. 1998. 75 f. Dissertação (Mestrado em Zoologia) - Setor de Ciências Biológicas, Universidade Federal do Paraná, Curitiba, 1998.

LANGE, R. B.; JABLONSKI, E. F. Lista prévia dos Mammalia do Estado do Paraná. Estudos Biologia, Curitiba, v. 6, p. 21, 1981.

LEONARD, M. Principaux anesthésiques injectables, volatiles et gazeux employés chez les carnivores domestiques. Le Point Véterinaire, v. 18, n. 102, p. 727$735,1986$.

LIN, M. T. et al. Effect of ketamine on thermoregulation in rats. Canadian Journal of Physiology and Pharmacology, v. 56, n. 1, p. 963-967, 1978.

MANDSAGER, R. E.; RAFFE, M. R. Chemical restraint techniques in dogs and cats. In: KIRK, R. W. Current 
veterinary therapy. 10. ed. Philadelphia: W. B. Saunders, 1989. p. 63-70.

MARGARIDO, T. C. C. Mamíferos do Parque Estadual de Castro, Paraná. 1989. 68 f. Dissertação (Mestrado em Zoologia) - Universidade Federal do Paraná, Curitiba, 1989

MASSONE, F. Anestesiologia veterinária - farmacologia e técnicas. Rio de Janeiro: Guanabara Koogan, 1988. 235 p.

MATTHEWS, N. S. et al. Anesthesia of Przewalski's horses (Equus przewalskii przewalskii) with medetomidine/ ketamine and antagonism with atipamezole. Journal of Zoo and Wildlife Medicine, v. 26, n. 2, p. 231-236, 1995.

McDONALD, L. E. Hormônios que afetam a reprodução. In: BOOTH, N. H.; McDONALD, L. E. Farmacologia e terapêutica em veterinária. Rio de Janeiro: Guanabara Koogan, 1992. p. 474-478.

MEYER-JONES, L. et al. Farmacologia e terapêutica em medicina veterinária. 4. ed. Rio de Janeiro: Guanabara Koogan, 1983. 1000 p.

MUIR, W. W.; HUBBEL, J. A. E. Handbook of veterinary anesthesia. 2. ed. St. Louis: Mosby, 1995. 510 p.

NAVARRO, J. A.; FRIEDMAN, J. R. A clinical evaluation of xylazine and ketamine $\mathrm{HCl}$ for cesarean section in the dog. Veterinary Medicine - Small Animal Clinician, v. 70 , n. 9 , p. $1075-1079,1975$.

NICHOLLS, P. K. et al. Anesthesia of the grey duiker (Sylvicapra grimmia) using a combination of ketamine and xylazine, with reversal by atipamezole. Journal of Zoo and Wildlife Medicine, v. 27, n. 1, p. 49-53, 1996.

OSOFSKY, S. A. et al. Immobilization of free-ranging african wild dogs (Lycaon pictus) using a ketamine/ xylazine/atropine combination. Journal of Zoo and Wildlife Medicine, v. 27, n. 4, p. 528-532, 1996.

PACHALY, J. R. Efeitos farmacológicos do cloridrato de cetamina em medicina veterinária. Revista do Setor de Ciências Agrárias, Curitiba, v. 13, n. 1-2, p. 151-156, 1994.

Estudo da utilização da associação cloridrato de cetamina, maleato de acetilpromazina e sulfato de atropina na contenção de Agouti paca Linnaeus, 1766 (Rodentia: Mammalia). Archives of Veterinary Science, v. 1, n. 1, p. $15,1996$.

Estudo da utilização da associação cloridrato de cetamina, maleato de acetilpromazina e sulfato de atropina na contenção de Agouti paca Linnaeus, 1766 (Rodentia:Mammalia). 1992. 70 f. Dissertação (Mestrado em Ciências Veterinárias) - Universidade Federal do Paraná, Curitiba, 1992.

Contenção da cutia, Dasyprocta azarae

(Rodentia: Mammalia), pela associação de cloridrato de cetamina, cloridrato de xilazina e sulfato de atropina: Definição de protocolos posológicos individuais com base em extrapolação alométrica interspecífica. 1998. 90 f. Tese. (Doutorado em Zoologia) - Setor de Ciências Biológicas, Universidade Federal do Paraná,Curitiba, 1998.

Terapêutica por extrapolação alométrica. In: CUBAS, Z. S. et al. Tratado de animais selvagens medicina veterinária. São Paulo: Roca, 2006. p. 12151223.

PACHALY, J. R. et al. Order Rodentia (Rodents). In: FOWLER, M. E.; CUBAS, Z. S. Biology, medicine and surgery of South American wild animals. Ames: lowa University Press, 2001. p. 225-237.

PACHALY, J. R.; BRITO, H. F. V. Interespecific allometric scaling. In: FOWLER, M. E.; CUBAS, Z. S. Biology, medicine and surgery of South American wild animals. Ames: lowa University Press, 2001. p. 475-481.

PAPICH, M. G. Table of common drugs: Approximate dosages. In: BONAGURA, J. D. Kirk's current veterinary therapy. 12. ed. Philadelphia: W. B. Saunders, 1995. p. $1429-1446$.

PLUMB, D. C. Veterinary drug handbook: computer edition. White Bear Lake: PharmaVet Publishing/Veterinary Software Publishing, 1991.

SAWYER, D. C. et al. Anesthetic principles and techniques. East Lansing: Michigan State University Press, $1977.80 \mathrm{p}$

SCHMIDT-NIELSEN K. Fisiologia animal: adaptação e meio ambiente. São Paulo: Santos 1996. 600 p.

SCHUCHMAN, S. M. Individual care and treatment of rabbits, mice, rats, guinea pigs, hamsters and gerbils. In: KIRK, R. W. Current veterinary therapy. 10. ed. Philadelphia: W. B. Saunders, 1989. p. 738-765.

SEDGWICK, C. J. Anesthesia for rabbits and rodents In: KIRK, R. W. Current veterinary therapy. 7. ed. Philadelphia: W. B. Saunders, 1980. p. 706-710.

SEDGWICK, C. J. Anesthetic and chemical restraint techniques for zoo animals and wildlife. In: ANNUAL MEETING OF THE AMERICAN ANIMAL HOSPITALS ASSOCIATION, 55., 1988, St Louis. Proceedings... St Louis: American Animal Hospitals Association , 1988. p. 162-166.

SEDGWICK, C. J. Field anesthesia in stressed animals. Modern Veterinary Practice, v. 60, n. 7, p. 531-537, 1979.

SEDGWICK, C. J.; POKRAS, M. A. Extrapolating rational drug doses and treatment periods by allometric scaling. In: ANNUAL MEETING OF THE AMERICAN ANIMAL HOSPITALS ASSOCIATION, 55., 1988, St Louis. Preceedings... St Louis: American Animal Hospitals Association , 1988. p. 156-161. 
SILVA, F. Mamíferos silvestres do Rio Grande do Sul. Porto Alegre: Fundação Zoobotânica do Rio Grande do Sul, 1984. p.171-209.

SOMA, L. R. Textbook of veterinary anesthesia. Baltimore: Williams and Wilkins, 1971. $621 \mathrm{p}$.

SOMA, L. R.; PENNEY, B. E. Sedation and general anesthesia. In: CATCOTT, E. J. Feline medicine and surgery. 2. ed. Santa Barbara: American Veterinary Publications, 1975. p. 527-549.

STOSKOPF, M. K. Anesthesia of zoo rodents. In: AMERICAN ASSOCIATION OF ZOO VETERINARIANS ANNUAL CONFERENCE, 1979, Denver. Preceedings... Denver: American Association of Zoo Veterinarians, 1979. p. 68-69.

STUNKARD, J. A.; MILLER, J. C. An outline guide to general anesthesia in exotic species. Veterinary Medicine Small Animal Clinician, v. 69, n. 9, p. 1181-1186, 1974.

THURMON, J. C.; BENSON, G. J. Pharmacologic consideration in selection of anesthetics for animals. Journal of the American Veterinary Medical Association, v. 191, n. 10, p. 245-1251, 1987.

TRANQUILI, W. J.; THURMON, J. C. Alpha adrenoceptor pharmacology. Journal of the American Veterinary Medical Association, v. 184, n. 11, p. 1440-1402, 1984.

TRANQUILLI, W. J.; BENSON, G. J. Advantages and guidelines for using alpha-2 agonists as anesthetic adjuvants. Veterinary Clinics of North America - Small Animal Practice, v. 22, n. 2, p. 289-293, 1983.

WALLACH, J. D.; BOEVER, W. J. Rodents and Lagomorphs. In: . Diseases of exotic animals: medical and surgical management. Philadelphia: W. B. Saunders, 1983. p. 135-147.

WHITE, P. F. et al. Ketamine: Its pharmacology and therapeutic uses. Anesthesiology, v. 56, n. 2, p. 119-136, 1982.

WHITE, W. J.; FIELD, K. J. Anesthesia and surgery of laboratory animals. Veterinary Clinics of North America - Small Animal Practice, v. 17, n. 5, p. 989-998, 1987.

WILSON, J. D. Androgens. In: HARDMAN, J. G.; LIMBIRD, L. E. Goodman and Gilman's: pharmacological basis of therapeutics. 9. ed. New York: McGraw-Hill, 1995. p. 1441-1455.

WIXSON, S. K. et al. A comparison of pentobarbital, fentanyl-droperidol, ketamine-xylazine and ketaminediazepam anesthesia in adult male rats. Laboratory Animal Science, v. 37, n. 6, p. 726-730, 1987.

WOODS, C. A. Suborder Hystricognathi. In: WILSON, D. E.; REEDER, D. M. Mammal species of the world: a taxonomic and geographic reference. 2. ed. Washington: Smithsonian Institution Press, 1992. p. 771-806.

WRIGHT, M. Pharmacologic effects of ketamine and its use in veterinary medicine. Journal of the American Veterinary Medical Association, v. 180, n. 12, p. 14621471, 1982.

Recebido em: 28/04/2014 Aceito em: 03/05/2014 